\title{
Diverse, rare microbial taxa responded to the Deepwater Horizon deep-sea hydrocarbon plume
}

\author{
Sara Kleindienst ${ }^{1,4}$, Sharon Grim ${ }^{2,5}$, Mitchell Sogin² ${ }^{2}$ Annalisa Bracco ${ }^{3}$, \\ Melitza Crespo-Medina ${ }^{1,6}$ and Samantha B Joye ${ }^{1}$

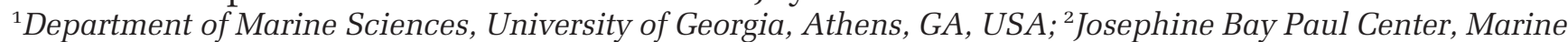 \\ Biological Laboratory, Woods Hole, MA, USA and ${ }^{3}$ School of Earth and Atmospheric Sciences, Georgia \\ Institute of Technology, Atlanta, GA, USA
}

\begin{abstract}
The Deepwater Horizon (DWH) oil well blowout generated an enormous plume of dispersed hydrocarbons that substantially altered the Gulf of Mexico's deep-sea microbial community. A significant enrichment of distinct microbial populations was observed, yet, little is known about the abundance and richness of specific microbial ecotypes involved in gas, oil and dispersant biodegradation in the wake of oil spills. Here, we document a previously unrecognized diversity of closely related taxa affiliating with Cycloclasticus, Colwellia and Oceanospirillaceae and describe their spatio-temporal distribution in the Gulf's deepwater, in close proximity to the discharge site and at increasing distance from it, before, during and after the discharge. A highly sensitive, computational method (oligotyping) applied to a data set generated from 454-tag pyrosequencing of bacterial 16S ribosomal RNA gene V4-V6 regions, enabled the detection of population dynamics at the sub-operational taxonomic unit level ( $0.2 \%$ sequence similarity). The biogeochemical signature of the deep-sea samples was assessed via total cell counts, concentrations of short-chain alkanes $\left(C_{1}-C_{5}\right)$, nutrients, (colored) dissolved organic and inorganic carbon, as well as methane oxidation rates. Statistical analysis elucidated environmental factors that shaped ecologically relevant dynamics of oligotypes, which likely represent distinct ecotypes. Major hydrocarbon degraders, adapted to the slow-diffusive natural hydrocarbon seepage in the Gulf of Mexico, appeared unable to cope with the conditions encountered during the DWH spill or were outcompeted. In contrast, diverse, rare taxa increased rapidly in abundance, underscoring the importance of specialized subpopulations and potential ecotypes during massive deep-sea oil discharges and perhaps other large-scale perturbations.

The ISME Journal (2016) 10, 400-415; doi:10.1038/ismej.2015.121; published online 31 July 2015
\end{abstract}

\section{Introduction}

The largest open ocean hydrocarbon discharge in history released unprecedented quantities of gas and oil into the deep ocean of the Northern Gulf of Mexico (hereafter referred to as the Gulf) following the explosion and sinking of the Deepwater Horizon (DWH) offshore drilling platform in 2010. Early during the DWH incident, before the damaged riser pipe was cut, hydrocarbon injection into the water column occurred as a pronounced jet that emerged

Correspondence: S Joye, Department of Marine Sciences University of Georgia, Room 220 Marine Sciences Building, Athens, GA, 30602-3636, USA.

E-mail: mjoye@uga.edu

${ }^{4}$ Present address: Center for Applied Geosciences, Eberhard-KarlsUniversity Tuebingen, 72074 Tuebingen, Germany.

${ }^{5}$ Present address: Department of Earth and Environmental Sciences, University of Michigan, Ann Arbor, MI, USA.

${ }^{6}$ Present address: Center for Environmental Education, Conservation and Research, Inter American University of Puerto Rico, San Juan, Puerto Rico.

Received 31 October 2014; revised 21 May 2015; accepted 3 June 2015; published online 31 July 2015 from the broken riser pipe, altering deepwater chemistry in the vicinity of the Macondo wellhead. The jet of oil and gas ascending into the water column entrained cold seawater (Johansen et al., 2001; Socolofsky et al., 2011) and generated a prolific hydrocarbon-rich deepwater plume that was detected to the southwest of the well by its fluorescence signature (Camilli et al., 2010; Diercks et al., 2010; Hazen et al., 2010), and light scattering profile (Diercks et al., 2010), as well as by elevated concentrations of specific hydrocarbons (Camilli et al., 2010; Diercks et al., 2010; Valentine et al., 2010; Joye et al., 2011; Kessler et al., 2011b; Reddy et al., 2012) and of the dispersant Corexit (Kujawinski et al., 2011). The deepwater plume spanned depths between 1000 and $1300 \mathrm{~m}$, in a region at least $35 \mathrm{~km}$ long by $2 \mathrm{~km}$ wide (Camilli et al., 2010).

Early in the DWH discharge, the hydrocarbonimpacted deep-sea waters hosted significantly enriched bacterial populations related to Oceanospirillum, Cycloclasticus, Colwellia, Pseudoalteromonas, Rhodobacterales and methylotrophs (Mason et al., 2012; Reddy et al., 2012; Redmond and Valentine, 2012; 
Valentine et al., 2012). In situ observations and laboratory findings signal that these bacteria played key roles in the biodegradation of oil in the plume. Compositional changes in hydrocarbon abundance implied preferential microbial utilization of oil-derived short-chain and higher-molecular weight alkanes (Valentine et al., 2010; Kessler et al., 2011b), whereas local dissolved oxygen anomalies (Joye et al., 2011; Kessler et al., 2011a, b) indicated extensive aerobic alkane respiration (Valentine et al., 2010; Crespo-Medina et al., 2014). Furthermore, stable-isotope probing and single-cell genomics identified microbial populations involved in hydrocarbon degradation or enrichment of metabolic genes that orchestrate hydrocarbon degradation in the plume, with Colwellia likely oxidizing ethane and propane (Redmond and Valentine, 2012), Oceanospirillum degrading cyclohexane (Mason et al., 2012) and Cycloclasticus utilizing polycyclic aromatic hydrocarbons (PAH) (Yakimov et al., 1998).

Descriptions of microbial communities using large marker gene data sets in combination with wellcharacterized environmental parameters offer a powerful method to evaluate the dynamic responses of bacterial assemblages to altered ecological conditions. The common approach of $16 \mathrm{~S}$ ribosomal RNA (rRNA) gene sequence taxon assignments typically relies on sequence similarity thresholds (for example, $97 \%$ ) to identify operational taxonomic units (OTUs), aiming to minimize the influence of random sequencing errors (Huse et al., 2010; Kunin et al., 2010). Although distribution patterns of OTUs among environmental samples are frequently used to infer ecological functions of microbial populations, this approach does not detect small variations in the $16 \mathrm{~S}$ rRNA gene sequence that reflects different ecotypes (Ward, 1998; Eren et al., 2013). The ecotype concept describes a collection of strains with subtly different genetic elements, which afford the ability to occupy slightly different ecological niches while preserving the genetic signature and the (nearly) full ecophysiological potential (Konstantinidis and Tiedje, 2005). Ecological distinctiveness of closely related populations could for instance be indicated by growth on a new substrate or by metabolic plasticity, for example, carrying out multiple metabolisms depending on environmental conditions (Konstantinidis et al., 2006). Such metabolic flexibility was almost certainly advantageous for diverse taxa present in the wake of the DWH spill, as, for example, closely related Colwellia ecotypes could have oxidized ethane, propane, and benzene or its metabolic byproducts (Redmond and Valentine, 2012).

To resolve environmentally relevant differences between sequences of closely related microbial taxa that respond to fluctuating geochemical conditions (for example ecotypes), bioinformatics approaches that allow sub-OTU resolution are required (Tikhonov et al., 2014). Oligotyping distinguishes subtle nucleotide variations within 16S rRNA gene amplicon reads that routine clustering strategies would converge into a single OTU (Eren et al., 2013). The ecologically powerful index of Shannon entropy ignores stochastic variation, for example, sequencing error, and uses information-rich sites to disaggregate similar sequences into oligotypes that represent discrete microbial populations in communities sampled from different ecological contexts. Dissimilarity thresholds for oligotypes can be as low as $0.2 \%$, versus the commonly used $3 \%$ obtained using OTU clustering.

In this work, we delved into the microbial diversity of the DWH deepwater hydrocarbon plume to an extent not attempted previously. We report an unrecognized level of diversity among key microorganisms involved in hydrocarbon degradation, and describe their spatio-temporal response to the oil, gas and dispersant infusion into the Gulf's deepwaters. Samples were obtained before, during and after the discharge, in close proximity to the discharge site and at increasing distance from it (Table 1). We surveyed microbial population dynamics of closely related taxa through oligotype analysis of bacterial $16 S$ rRNA genes. The geochemical signature of the plume fluids characterized the environmental factors that drove the observed remarkable shifts in relative abundance for closely related microbial taxa, which likely represent distinct ecotypes.

\section{Materials and methods}

\section{Study sites}

Samples were obtained from the northern Gulf of Mexico (Table 1,Supplementary Figure S1), on cruises R/V Pelican (PE 10-20, March 2010), R/V Walton Smith (WS1010, May/June 2010), R/V Oceanus (OC468-2, September 2010), R/V Atlantis (AT18-2, November 2010), R/V Endeavor (EN496, July 2011), R/V Endeavor (EN510, June 2012) and R/V Falkor (FA006, November 2012). The DWH wellhead is located in Mississippi Canyon block 252 (latitude 28.7381, longitude -88.3659; hereafter MC252). Samples impacted by the DWH discharge were taken within the plume (water depth from 1000 to $1300 \mathrm{~m}$ ), above the plume or below the plume. In addition, we sampled different locations over an area of approximately $105000 \mathrm{~km}^{2}$ to assess the impact of the deepwater plume. For ease of sample identification, samples were numbered (1-20) and designated as 'PRE', 'DUR' and 'POST' to indicate the time of sampling relative to the spill (pre-, during and postdischarge), followed by the site of sampling (indicated by the site's lease block number, as defined by the Bureau of Ocean Energy Management). Original cruise sample designations are given in Table 1. Samples were characterized by differences in the magnitude of gas and oil release as a function of time of sampling (Supplementary Table S1). A unique sample was taken in November 2012 directly in the DWH-impacted area (19-POSTMC252); to the best of our knowledge, this is the 


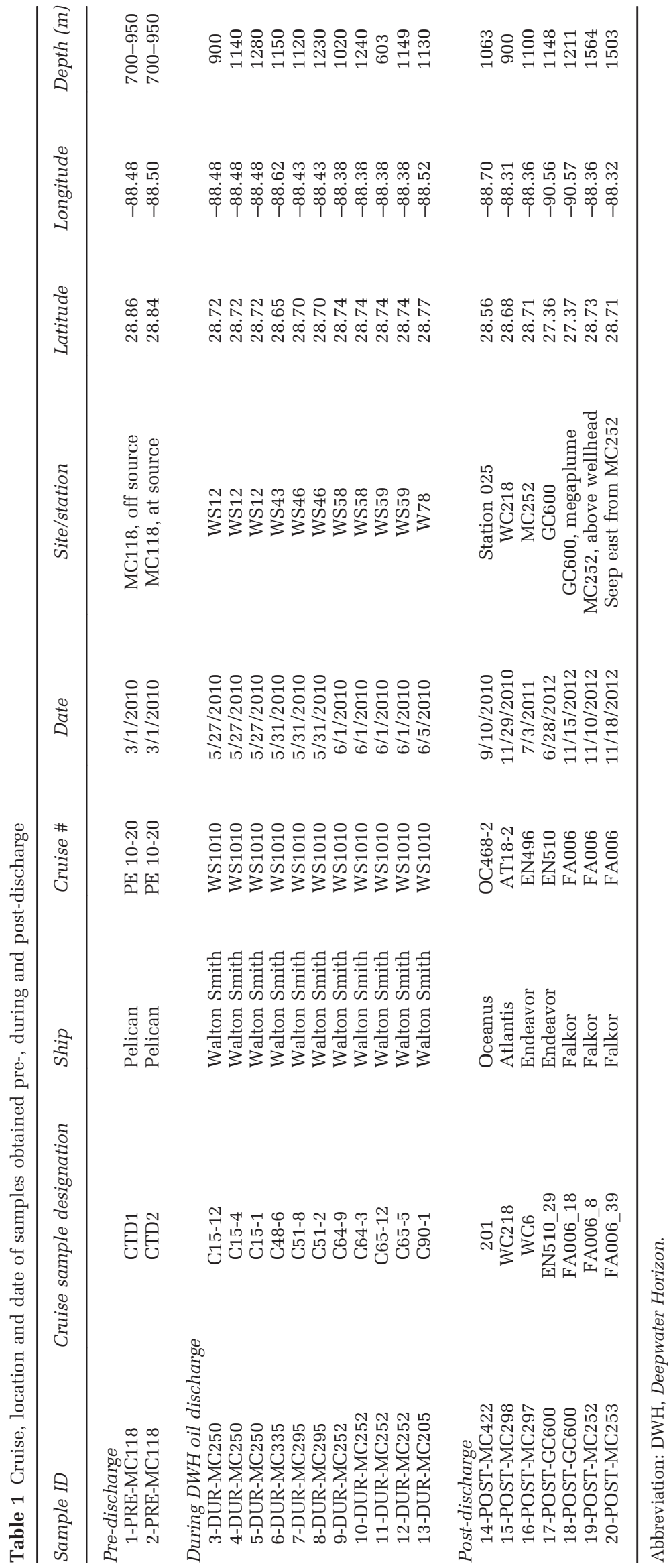


closest sample to the wellhead recovered to date (distance to wellhead was $72 \mathrm{~m}$ ). Another unique sample (20-POST-MC253) was obtained from a newly discovered seep located slightly east of MC252. The source of this seep remains hypothetical, however, it could derive from the MC252 reservoir. Both samples (19-POST-MC252 and 20POST-MC253) likely reflect a mixture pelagic and benthic microbial communities, because the seawater was retrieved close to the sediment surface and, based on visual observation during remotely operated vehicle sampling, contained some sediment particles. Time series sampling between March 2010 through November 2012 allowed us to estimate the extent of the disruption and re-establishment of the endemic pelagic microbial population by the DWH event. Moreover, natural hydrocarbon seep sites in the northern Gulf were sampled to elucidate gas and oil-degrading background microbial communities prevalent in the Gulf's deepwater environment.

Seep sites located at Mississippi Canyon block 118, hereafter referred to as MC118, are located about $150 \mathrm{~km}$ south of Pascagoula, MS, (mean latitude 28.8522, mean longitude -88.4928) and $26 \mathrm{~km}$ northnorthwest from MC252 at a water depth of $900 \mathrm{~m}$. Seeps at MC118 were impacted by the deepwater plume, however, we sampled at this site 1 month before the DWH oil discharge began, in March 2010 (1-PRE-MC118 and 2-PRE-MC118; Table 1). These samples from MC118 reflected the natural pelagic background seep community that is endemic to this area where the deepwater hydrocarbon plume dispersed some 6-8 weeks later. In general, MC118 seeps are characterized by natural gas and oil discharge, chemosynthetic communities including Beggiatoa (Lloyd et al., 2010), methane-ice worms, and chemosymbiotic mussels and clams, indicating high hydrocarbon fluxes and high background rates of microbial activity (Bowles et al. 2011).

Like MC118, seep sites located at Green Canyon block 600, hereafter GC600, are characterized by extensive gas and oil seepage, seep macrofauna (including chemosymbiotic clams and mussels) as well as microbial mats that colonize the sediment surface and abundant carbonate outcrops (Roberts et al., 2010). The GC600 area is $260 \mathrm{~km}$ southwest of MC252 (mean latitude 27.3696, mean longitude -90.5693) and was not directly impacted by the DWH deepwater plume. Samples taken at GC600 (17-POSTGC600 and 18-POST-GC600; Table 1) represent natural pelagic seep communities in the aftermath of the DWH oil discharge (June and November 2012). GC600 is one of the most active natural oil seeps in the Gulf of Mexico at a water depth of $1250 \mathrm{~m}$ and was described in detail previously (Joye et al., 2010; Roberts et al., 2010; Hu et al., 2012).

\section{Sample collection}

A CTD rosette instrumented to measure conductivity (salinity), temperature, depth, chlorophyll fluorescence, beam transmission, as well as oil fluorescence, equipped with twelve 10 liter $(R / V S$ Walton Smith, Pelican) or twenty-four 20 liter $(R / V s$ Oceanus, Atlantis, Endeavor, Falkor) Niskin bottles, was used to collect water samples. Additional water samples were collected using 1 liter Niskin bottles attached to a remotely operated vehicle or a multiple corer. After recovery of the rosette or individual Niskin bottles (remotely operated vehicle/multiple corer), water samples were collected by attaching a section of clean (acid-rinsed, Milli-Q rinsed and dried) silicon tubing to the port and draining water into a precleaned (HCl-soaked, MQ rinsed and dried) bottle. Bottles were sample rinsed three times before filling. In the laboratory, sub-samples for cell counts, molecular analyses and geochemistry were collected. Cell count samples were fixed with formalin (final concentration 4\%) and stored at $-20^{\circ} \mathrm{C}$ until analysis. For molecular analysis, cells were concentrated by filtering 1 liter of seawater through a sterivex filter using a peristaltic pump. Filters were flash frozen in liquid nitrogen and stored at $-80^{\circ} \mathrm{C}$ until DNA extraction. Except for the $\mathrm{CH}_{4} /$ short-chain alkane sub-samples, geochemistry samples were removed from the bottle using a syringe, then passed through a $0.2 \mu \mathrm{m}$-filter (Gelman Acrodisk or Target cellulose) and subsequently aliquoted and fixed for various analyses (see Geochemistry section). All geochemistry sample vials were acid-washed, rinsed with ultrapure water and combusted at $500{ }^{\circ} \mathrm{C}$ before use.

\section{Geochemistry}

Sample $\mathrm{pH}$ was determined immediately using a highimpedence electrometer calibrated with certified standards. For the analysis of ammonium $\left(\mathrm{NH}_{4}^{+}\right)$concentration, $1 \mathrm{ml}$ of $0.2 \mu \mathrm{m}$-filtered sample was preserved with $200 \mu \mathrm{l}$ of phenol reagent; the fixed sample was stored at $4^{\circ} \mathrm{C}$ and analyzed within 1-2 days using the indo-phenol colorimetric method (Solorzano, 1969). Samples for nutrients $\left(\left(\mathrm{NO}_{\mathrm{x}}^{-}=\right.\right.$nitrate $\left(\mathrm{NO}_{3}^{-}\right)+$nitrite $\left(\mathrm{NO}_{2}^{-}\right)$, nitrite $\left(\mathrm{NO}_{2}^{-}\right)$and phosphate $\left(\mathrm{PO}_{4}^{3-}\right)$ ) and dissolved organic carbon were passed through a $0.2 \mu \mathrm{m}$ filter into clean Nalgene bottles and frozen at $-20^{\circ} \mathrm{C}$ until analysis, as described previously (Joye et al., 2004). Dissolved organic carbon was measured using a Shimadzu total organic carbon analyzer (TOCV; Shimadzu Corporation, Kyoto, Japan) on acidified $(\mathrm{pH}<2)$ samples after sparging with $\mathrm{CO}_{2}$-free air for 15 min. Filter (Gelman Acrodisk and Target cellulose filters) blanks (milliQ water passed through the filters) for dissolved organics were run in parallel and were found to be inconsequential.

For quantification of methane or short-chain alkanes (ethane, propane, butane and pentane), gases were recovered via either head space extraction (R/Vs Pelican, Walton Smith cruises) or from a $750 \mathrm{ml}$ water sample using vacuum sonication (all other cruises) (Crespo-Medina et al., 2014). The volume of recovered gas was recorded and the 
gas sample was transferred quantitatively to a serum vial; alkanes were later quantified using gas chromatography. For the analysis of dissolved inorganic carbon, $1 \mathrm{ml}$ of $0.2 \mu \mathrm{m}$-filtered sample was injected into a He-purged and crimp-sealed $6 \mathrm{ml}$ headspace vial, which was then acidified with $0.1 \mathrm{ml}$ of concentrated phosphoric acid. Methane or shortchain alkanes (methane, ethane, propane, butane and pentane) and dissolved inorganic carbon were measured on a gas chromatograph equipped with a flame ionization detector (Shimadzu GC 14A with a $0.5 \mathrm{~m}$ Haysep DB pre-column and a $2 \mathrm{~m}$ Carbosphere column (Alltech Instruments, Deerfield, IL, USA)) and a methanizer (Shimadzu) to convert carbon dioxide to methane for precise quantification. The isotopic composition of dissolved inorganic carbon was determined using a Picarro $\mathrm{iCO}_{2}$ cavity ring down spectroscopy system with a precision of $0.5 \%$. Colored dissolved organic matter, a good proxy for dissolved oil (Diercks et al., 2010), was quantified using a WetLabs ECO-FL fluorometer (Philomath, OR, USA) mounted on the rosette frame.

\section{Methane oxidation rates}

Methane oxidation rates were measured using a tritiated $\left({ }^{3} \mathrm{H}\right) \mathrm{CH}_{4}$-radiotracer technique (Carini et al., 2005, Crespo-Medina et al. 2014). For each depth sampled, seawater samples (triplicate $(n=3)$ live samples and one killed control) were collected with Tygon-tubing attached to a syringe and filled, bottom to top, without air-bubbles into $7 \mathrm{ml}$ glass scintillation vials allowing overflowing of the sample, to fill the vial without headspace. For the control samples, $500 \mu \mathrm{l}$ of ethanol (96\%) was added immediately to halt microbial activity. Vials were immediately sealed with butyl rubber septa free of bubbles that were secured with a screw cap; samples were stored at $4{ }^{\circ} \mathrm{C}$ until tracer injection (usually within 12-36 h). In some cases, storage for longer periods of time before rate determination was required (for example, on cruises lacking a radioisotope isolation van); we found that storage for up to several weeks did not alter methane oxidation rates (see Addendum to Crespo-Medina et al. 2014). A $100 \mu l$ aliquot of $\mathrm{C}^{3} \mathrm{H}_{4}$-tracer solution was injected into each sample through the butyl septa using a gas-tight syringe, yielding a tracer activity of $\sim 75000$ d.p.m. per $\mathrm{ml}^{-1}$ sample. Samples were incubated for $48 \mathrm{~h}$ at in situ temperature in the dark. Incubations were terminated by amending samples with $200 \mu \mathrm{l}$ of ethanol, which served to halt biological activity. Labeled $\mathrm{C}^{3} \mathrm{H}_{4}$ was removed by purging the sample with hydrated air for at least $25 \mathrm{~min}$. Scintillation cocktail (Scintiverse BD, Fisher Scientific, Hampton, NH, USA) was added and samples were counted for ${ }^{3} \mathrm{H}_{2} \mathrm{O}$ activity using a Beckman 6500 liquid scintillation counter (Beckman Coulter, Brea, CA, USA). Methane oxidation rate constants $(\mathrm{k})$ were calculated according to

$$
k=\left[\mathrm{A}_{3 \mathrm{H} 20} / A_{\mathrm{C} 3 \mathrm{H} 4}+A_{3 \mathrm{H} 20}\right] / t
$$

(where $\mathrm{A}=$ activity and $\mathrm{t}=$ time) and multiplied by the in situ $\mathrm{CH}_{4}$ concentration to determine the methane oxidation rates.

\section{Total cell counts, DNA extraction and 454} pyrosequencing

Total counts of individual cells were done via epifluorescence microscopy after staining with acridine orange (AODC) according to standard methods (Hobbie et al., 1977). DNA extraction was performed from the entire sterivex filter (see Sample collection section) using the Gentra Puregene Kit (Qiagen, Valencia, CA, USA) as described previously (Sinigalliano et al., 2007), in combination with a lytic enzyme solution (Qiagen; Zettler, 2013). DNA extracts were stored at $-80^{\circ} \mathrm{C}$ until PCR amplification. The 16S rRNA gene V3-V5 and V4-V6 regions were analyzed with tag pyrosequencing (Thor Marteinsson et al., 2013). We performed quality control and trimming of sequence reads as described previously (Huse et al., 2010) and assigned taxonomy using Global Alignment for Sequence Taxonomy (GAST; Huse et al., 2008) and a Marine Biological Laboratory (MBL)-curated SILVA database version 108 (Quast et al., 2013). Traces were submitted to sequence read archive and are available under the Bioproject ID PRJNA234441.

OTU clustering, taxonomic identification, diversity and Morisita-Horn indexes and phylogenetic analysis All sequences were anchor trimmed to minimize sequencing error artifacts. To achieve this, V3V5 and V6V4 reads (Supplementary Table S2) were trimmed to a conserved region (read length of 371 or 362 base pairs, respectively). Subsequently, we used UCLUST (Edgar, 2010) to cluster the sequences into OTUs based on a $97 \%$ similarity threshold (Supplementary Table S3). Representative sequences from each cluster were selected and taxonomy was assigned with GAST (Huse et al., 2008).

To determine diversity indexes (Good's coverage, Shannon's Index, Richness, Evenness, Inverse Simpson) and Morisita-Horn indexes, we used R (R-CoreTeam, 2012) and the vegan package (Oksanen et al., 2013; Supplementary Table S4). Two samples had substantially lower read counts (6-DUR-MC335, 8217 reads and 17-POST-GC600, 84 reads) than all other samples ( $>21500$ reads) and were therefore not rarefied. Rarefication for all other samples was calculated 100 times, generating 100 OTU tables that were averaged to present the mean rarefied observation of each OTU in each sample. Mann-WhitneyWilcoxon analyses verified that rarefied data were not statistically different from the unrarefied data $(P=0.8252)$. Alpha diversity indexes were calculated for the non-rarefied OTU table, a random rarefied OTU table and the averaged (100 calculations) rarefied OTU table. The diversity estimates (Supplementary Table S4) changed only slightly 
between the non-rarefied and the rarefied OTU tables. To retain information for oligotyping, we proceeded with the non-rarefied OTU table. We converted sequence observations to relative abundance data, scaled from 0 to $100 \%$ of the community, and Morisita-Horn beta diversity indexes were calculated for all OTUs and all oligotypes (see below), as well as for Colwellia, Oceaniserpentilla, Cycloclasticus and SAR11 oligotypes, separately.

For phylogenetic analyses, we used the ARB software package (Ludwig et al., 2004) with the database SSURef111 from ARB SILVA (Pruesse et al., 2007). Phylogenetic trees of nearly full-length 16S rRNA gene sequences were calculated by maximum-likelihood analysis and oligotype sequences were subsequently inserted into the tree by parsimony criteria, without allowing changes in the overall tree topology.

\section{Oligotyping}

We used oligotyping (Eren et al., 2013) to evaluate V6V4 sequences assigned to Colwellia (26217 sequences), Oceaniserpentilla (168 045 sequences) and Cycloclasticus (41 714 sequences) genera and on the SAR11 (64701 sequences) at the nucleotide level. These microbial groups were ubiquitous and widely distributed over the time series, and the Colwellia, Oceaniserpentilla and Cycloclasticus are key members of the oil-degrading microbial assemblage, making them ideal candidates for micro-diversity examination via oligotyping.

All sequences observed in the samples that resolved to each genus of interest were extracted, aligned to a template consisting of the full-length $16 \mathrm{~S}$ rRNA sequences of that target genus, and trimmed to a consistent start and end position. Entropy at each nucleotide position was calculated, and between 13 and 19 information-rich positions contributed to the oligotyping. Sequencing proceeded from the V6 toward the V4 region, with increasing error along the length of the read ( $>450 \mathrm{bp}$ ), so we limited highentropy locations of interest to the lowest noise areas in the V6, V5 and the end of V4 regions. We retained oligotypes that were observed in a minimum of $10 \%$ of samples in which the genus appeared, were $0.1 \%$ or more abundant in at least one sample, and in which the most abundant unique sequence was $0.05 \%$ of all reads in that genus. A detailed example of the oligotyping procedure is described in the Supplementary Materials.

As with the full OTU data set, we compared the effects of rarefying the resulting oligotype abundance table. Rarefying the table to the lowest read count of a sample (32, for 17-POST-GC600) generated a statistically different profile (MWW, $P<0.01$ ). Rarefying to the next lowest depth (2856, 1-PRE-MC118) was not statistically different from the full oligotype community profile (MWW, $P=0.5101$ ), and discarded $80 \%$ of oligotype sequences. Correlation tests between environmental parameters and rarefied data yielded over twice as many relationships as analyses with unrarefied oligotype abundances (data not shown). To reduce the risk of false positives, we did not use the rarefied data in the oligotyping analysis.

\section{Statistical analysis}

We evaluated relationships between measured environmental parameters and oligotype abundances using R (R-Core-Team, 2012), packages vegan (Oksanen et al., 2013) and q-value (Klaus and Strimmer, 2012). Spearman's nonparametric rank correlation coefficient $\rho$ was calculated for each oligotype distribution and environmental parameter. Storey's false discovery rate correction for multiple tests at $\mathrm{q}<0.05$ was used to retain significant $(P<0.05)$ correlations.

\section{Results and Discussion}

\section{Geochemical signatures of the DWH}

In the Gulf, slow and diffuse natural seepage of gas and crude oil from the sea floor (Behrens, 1988; Kennicutt II et al., 1988; Aharon, 1994) sustains active hydrocarbon-degrading microbial communities such as sulfate-reducing and methaneoxidizing bacteria (Orcutt et al., 2010; Kleindienst et al., 2012). In striking contrast to the slow natural gas and oil inputs, the DWH oil discharge released $2.6-3.6 \times 10^{5}$ t gas and $5.9-8.4 \times 10^{5}$ t oil (Joye et al., 2011; McNutt et al., 2012), exposing the Gulf's microbial populations to locally unprecedented hydrocarbon loads. The temporal impact of the deepwater plume on the native bacterial communities was surveyed between March 2010 and November 2012, in conditions hereafter termed 'pre-discharge' (PRE), 'discharge' (DUR) and 'postdischarge' (POST). Biogeochemical and hydrographic data (Supplementary Table S1) defined the core of the plume. 'Plume samples' exhibited methane concentrations $>10 \mu \mathrm{M}$ and/or water depths between 1000 to $1300 \mathrm{~m}$ (during the discharge), whereas 'non-plume samples' exhibited lower methane concentrations but still held evidence of impact by the DWH oil discharge (methane concentrations $>10 \mathrm{~nm}$ but $<10 \mu \mathrm{M}$ and water depths above $1000 \mathrm{~m}$ or below $1300 \mathrm{~m}$ ). To compare plume populations with native oil-degrading bacterial communities, we obtained deepwater samples from two natural hydrocarbon seeps, MC118 and GC600 (Orcutt et al., 2005; Bowles et al., 2011).

\section{Propagation of the deep-sea plume}

Our sample locations are clustered to the southwest of the wellhead. The propagation of the deepwater plume to the southwest is consistent with the counter clockwise current that contributes the mean circulation of the northern Gulf along the continental slope. However, cyclonic and anticyclonic eddies of 
up to $40 \mathrm{~km}$ in diameter are continuously generated in the region through instabilities of the mean current interacting with the complex bathymetry (Cardona and Bracco, 2015), and they may have moved the plume in other directions, at least sporadically, as well. Numerical integrations with a regional ocean model suggested that the plume pattern and direction changed with time, shifting to the southwest after propagating to the northeast for about a week, such that water parcels in the plume came in contact with the hydrocarbon source multiple times (Valentine et al., 2012). As a result of the chaotic nature of the circulation around the wellhead, it is not possible to calculate how long it took for the microbial community to be altered, or to evaluate how many times water in the immediate vicinity of the wellhead (that is, within $5 \mathrm{~km}$ radius) was in contact with the discharging hydrocarbon jet. However, clearly, the water we sampled in May/June 2010 was directly impacted by the discharging hydrocarbon jet and the after effects of this exposure was apparent in samples collected well past the time when the well was capped (July 2010).

\section{Alteration of the microbial community following the discharge}

The microbial community was analyzed based on 454-tag pyrosequencing of the V3V5 and V6V4 regions of the 16S rRNA gene (Supplementary Table S2). A comparison of taxonomic identifications using these two regions indicated that the selection of variable region influenced the numbers of calculated OTUs, although the same general trends for minor and dominant populations were observed for either V3V5 and V6V4, independent of the choice of sequenced region (Supplementary Table S3). As the V6V4-based sequencing provided a more comprehensive data set, it was subsequently selected for in-depth analysis.

Morisita-Horn indexes based on relative abundances of all OTUs were used to measure microbial community dissimilarities among samples. The water sample we retrieved from the nearest point to the wellhead during the discharge $-<0.5 \mathrm{~km}$ away-reflected a microbial community with substantial signs of alteration (11-DUR-MC252, 10-DURMC252, 12-DUR-MC25 and 9-DUR-MC252; Figure 1) compared with the background community (1-PREMC118 and 2-PRE-MC118; Morisita-Horn index 0.2-1; Figure 1a). Three of the samples near the DWH site (11-DUR-MC252, 10-DUR-MC252 and 12-DUR-MC252) were also distinct from the downstream, that is, samples collected 7 to $27 \mathrm{~km}$ from the wellhead, microbial community (Morisita-Horn index 0.1-0.9; Figure 1a). A comparison of samples at same locations but different depths showed that the plume was confined vertically to a layer centered just below $1000 \mathrm{~m}$ near the DWH discharge site, and that it dispersed over a broader depth as it moved into deeper waters to the southwest. As a result, the microbial community in the core of the plume near the wellhead (9-DUR-MC252) is similar to populations in other plume samples, despite a minimum of 3 days separation in the waters at block 335 (6-DURMC335) from the discharging well using horizontal velocity estimates from (Camilli et al., 2010), and that our samples downstream from and close to the well were taken 2 days apart and in reverse-with respect to the flow direction-chronology.

Consistent with previous studies (Hazen et al., 2010; Redmond and Valentine, 2012; Valentine et al., 2012), comparing all OTUs among samples we observed shifts in microbial community composition in plume samples compared with non-plume samples, and significantly reduced diversity within the plume. For instance, sequences from predischarge samples clustered into 811 and 980 bacterial OTUs (1-PRE-MC118 and 2-PRE-MC118, respectively), whereas plume-impacted areas (7-DUR-MC295，9-DUR-MC252，8-DUR-MC295 and 6-DUR-MC335) had lower numbers of bacterial OTUs (199-548; Supplementary Table S3). At the expense of overall community richness, the DWH plume enriched specific microbial populations and reduced microbial diversity. Although specific organisms and/or populations potentially thrived under plume conditions, such as high concentrations of short-chain alkanes (Joye et al., 2011; Supplementary Table S1), longer alkanes, PAH (Reddy et al., 2012) and dioctyl sodium sulfosuccinate (Kujawinski et al., 2011), other components of the microbial population exhibited reduced abundance, fell below detection, or potentially became inactive and/or died both at the wellhead and downstream of it. In contrast, the highest numbers of bacterial OTUs were observed in after-discharge samples from a prolific natural methane plume at seep, GC600 (18-POST-GC600; 1640 OTUs). The 2012 samples retrieved from the wellhead area were likely influenced by pelagic and benthic microorganisms because sediments were disturbed slightly during bottom water sampling (19-POST-MC252 and 20-POST-MC253, 2997 and 6835 OTUs, respectively).

\section{Response of bacterial populations and their putative} role in oil biodegradation

Actinobacteria, Bacteroidetes, Chloroflexi, Deferribacteres, SAR11, SAR324 and SAR86 dominated pre-discharge samples (1-PRE-MC118 and 2-PREMC118; Figure 2). Those groups are typically observed in pelagic ocean waters (Swan et al., 2011). During the DWH oil discharge, in May and June 2010, cell numbers in plume samples increased by an order of magnitude compared with background deep seawater (up to $2 \times 10^{6}$ cells ml ${ }^{-1}$ from $1-2 \times 10^{5}$ cells $\mathrm{ml}^{-1}$; Supplementary Table S1), which suggests increased growth rates fueled by the infusion of gas and oil. At this time, Gammaproteobacteria constituted $43-98 \%$ of all sequences in plume samples (Figure 2, Supplementary Table S3), against 
a

\begin{tabular}{|c|c|c|c|c|c|c|c|c|c|c|c|c|c|c|c|c|c|c|c|c|c|}
\hline \multirow[t]{2}{*}{ JTUs } & \multirow[b]{2}{*}{ Samples } & \multicolumn{2}{|c|}{ Pre-DC } & \multicolumn{11}{|c|}{ uring discharge } & \multicolumn{7}{|c|}{ Post-discharge } \\
\hline & & & 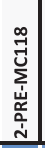 & 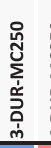 & 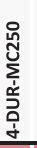 & 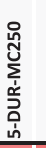 & 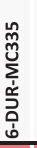 & 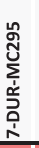 & 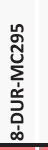 & 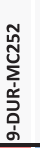 & 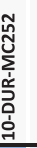 & 7 & 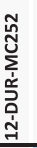 & 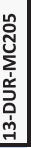 & 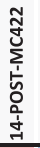 & 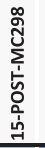 & 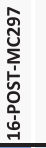 & 衣 & 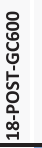 & & \\
\hline & 8 & 0 & 0.0 & $0.1 / 1$ & 1.0 & $1.0 \mid 1$ & 1.0 & 1.0 & 1.0 & 1.0 & 0.3 & 0.7 & 0.8 & 0.5 & 0.9 & 0.3 & 0.1 & 0.6 & 0.8 & 0.2 & \\
\hline & 18 & $0.0 \mid$ & 0 & .13 & 1.0 & $0.9 \mathrm{c}(\mathrm{c}) \mathrm{c}$ & 0.9 & 1.0 & 1.0 & 1.0 & 0.2 & 0.6 & 0.8 & 0.5 & 1.9 & 0.3 & 0.1 & 0.6 & 0.8 & 0.2 & \\
\hline & & 0.1 & $0.1 \mid$ & 0 & 0.8 & 0.8 & (3) & 9 & 0.9 & 0.9 & 0.1 & 0.5 & 0.6 & 0.3 & 9 & 0.2 & 0.1 & 5 & 0.9 & 0.2 & \\
\hline & 4-DUR & 1.0 & 1.0 & 0.8 & 0 & 0.7 & 0.8 & 0.1 & 0.1 & 0.0 & 0.7 & 0.3 & 0.3 & 0.5 & 1.0 & 1.0 & 1.0 & 1.0 & 1.0 & 1.0 & \\
\hline & 5-DUR- & 1.0 & 0.9 & 0.8 & 0.7 & 0 & 0.0 & 0.8 & 0.9 & 0.7 & 0.8 & 0.8 & 0.8 & 0.6 & 0.9 & 1.0 & 1.0 & $1.0 \mid$ & 1. & 0.9 & \\
\hline & 6-DUR-1 & 1.0 & 0.9 & 0.9 & 0.8 & 0.0 & 0 & 0.9 & 1.0 & 0.8 & 0.9 & 0.9 & 0.9 & 0.7 & 0.9 & 1.0 & $1.0 \mid 1-3=1$ & $1.0 \mid$ & 1.0 & 0.9 & \\
\hline & 7-DUR-MC295 & 1.0 & 1.0 & 0.9 & 0.1 & 0.8 & 0.9 & 0 & 0.0 & 0.0 & 0.8 & 0.5 & 0.4 & 0.6 & 1.0 & 1.0 & $1.0 \mathrm{~J}$ & 1.0 & 1.0 & 1.0 & \\
\hline & 8-DUR-MC295 & 1.0 & 1.0 & 0.9 & 0.1 & 0.9 & 1.0 & 0.0 & 0 & 0.0 & 0.8 & 0.5 & 0.4 & 0.6 & 1.0 & 1.0 & 1.0 & 1.0 & 1.0 & 1.0 & \\
\hline & 9-DUR-MC252 & 1.0 & 1.0 & 0.9 & 0.0 & 0.7 & 0.8 & 0.0 & 0.0 & 0 & 0.8 & 0.4 & 0.3 & 0.6 & 1.0 & 1.0 & $1.0 \mathrm{~J}$ & 1.0 & 1.0 & 1.0 & \\
\hline & 10-DUF & 0.3 & 0.2 & 0.1 & 0.7 & 0.8 & 0.9 & 0.8 & 0.8 & 0.8 & 0 & 0.3 & 0.4 & 0.1 & 0.9 & 0.4 & 0.2 & 0.6 & 0.9 & 0.2 & \\
\hline & & 0.7 & 0.6 & 0.5 & 0.3 & 0.8 & 0.9 & 0.5 & 0.5 & 0.4 & 0.3 & 0 & 0.1 & 0.1 & y & 0.7 & 0.7 & 0.8 & 0. & 0.1 & \\
\hline & 52 & 0.8 & 0.8 & 0.6 & 0.3 & 0.8 & 0.9 & 0.4 & 0.4 & 0.3 & 0.4 & 0.1 & 0 & 0.2 & 0 & 0.9 & $0.9 \mathrm{c}$ & 0.9 & 1. & 0.8 & \\
\hline & 05 & 0.5 & 0.5 & 0.3 & 0.5 & 0.6 & 0.7 & 0.6 & 0.6 & 0.6 & 0.1 & 0.1 & 0.2 & 0 & 0.9 & 0.6 & 0.5 & 0.7 & 0.9 & 0.5 & \\
\hline & & 0.9 & 0.9 & 0.9 & 1.0 & 0.9 & 0.9 & 1.0 & 1.0 & 1.0 & .9 & 0.9 & 1.0 & 0.9 & 0 & 0.8 & 0.9 & 0.6 & 0.8 & 0.8 & \\
\hline & 98 & 0.3 & 0.3 & 0 & 1.0 & 1.0 & 1. & 1.0 & 1.0 & 1. & 0.4 & & 9 & 6 & 0.8 & 0 & 0.1 & 0.2 & 0.8 & 0.3 & \\
\hline & 16-POST-MC297 & 0.1 & 0.1 & 0.1 & 1.0 & 1.0 & 1.0 & 1.0 & 1.0 & 1.0 & 0.2 & 0.7 & 0.9 & 0.5 & 0.9 & 0.1 & 0 & 0.4 & 0.8 & 0.1 & \\
\hline & 0 & 0.6 & 0.6 & L & 1.0 & 1.0 & 1.0 & 1.0 & 1.0 & 1.0 & 0.6 & o. & 0.9 & 0.7 & 0 & 0.2 & 0.4 & 0 & 0.8 & 0.5 & \\
\hline & (1) & 0.8 & 0.8 & & 1.0 & 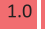 & & & 1.0 & & & & & & & 0.8 & 0.8 & 0.8 & 0 & 0.9 & \\
\hline & 52 & 0.2 & $0.2 \mid$ & $0.2 \mid$ & 1.0 & 0.9 & 0.9 & 1.0 & $1.0 \mid$ & 1.0 & 0.2 & 0.7 & 0.8 & 0.5 & 0.8 & 0.3 & 0.1 & 0.5 & 0.9 & 0 & 0. \\
\hline & 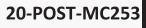 & & | & .0.4 & 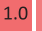 & 1.0 & 1. & & $1.0 \mid$ & & 0. & 0.8 & & 0.6 & 0.9 & 0.4 & 0.2 & & 0.9 & 0.1 & \\
\hline
\end{tabular}

b

\begin{tabular}{|c|c|c|c|c|c|c|c|c|c|c|c|c|c|c|c|c|c|c|c|c|c|}
\hline \multicolumn{2}{|c|}{ Oligotypes } & \multicolumn{2}{|c|}{ Pre-DC } & \multicolumn{11}{|c|}{ During discharge } & \multicolumn{7}{|c|}{ Post-discharge } \\
\hline & Samples & 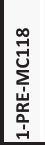 & 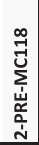 & 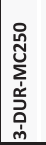 & 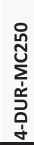 & 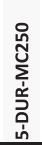 & 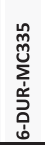 & 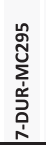 & 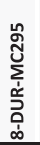 & & 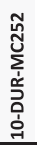 & $\overbrace{}^{2}$ & 实 & 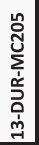 & 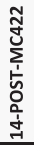 & 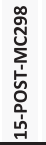 & 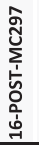 & 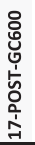 & 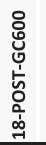 & & 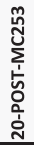 \\
\hline \multirow[t]{2}{*}{ प̆ } & 1-PRE-MC118 & 0 & 0.2 & 0.6 & 1.0 & 1.0 & 1.0 & 1.0 & 1.0 & 1.0 & 0.8 & 1.0 & 1.0 & 0.9 & 0.8 & 0.3 & 0.3 & 0.5 & 0.3 & 0.4 & \\
\hline & 2-PRE-MC118 & 0.2 & 0 & 0.5 & 1.0 & 0.7 & 0.8 & 1.0 & 1.0 & 1.0 & 0.7 & 0.9 & 1.0 & 0.8 & 0.8 & 0.3 & 0.3 & 0.6 & 0.3 & 0.4 & \\
\hline \multirow{11}{*}{ 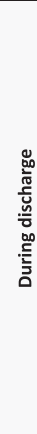 } & 3-DUR-MC250 & 0.6 & 0.5 & 0 & 0.5 & 0.5 & 0.7 & 0.6 & 0.7 & 0.6 & 0.1 & 0.5 & 0.6 & 0.3 & 0.8 & 0.5 & 0.5 & 0.7 & 0.5 & 0.5 & \\
\hline & 4-DUR-MC250 & 1.0 & 1.0 & 0.5 & 0 & 0.7 & 0.8 & 0.0 & 0.1 & 0.0 & 0.3 & 0.0 & 0.0 & 0.1 & 1.0 & 1.0 & 1.0 & 1.0 & 1.0 & 1.0 & 1. \\
\hline & 5-DUR-MC250 & 1.0 & 0.7 & 0.5 & .7 & 0 & 0.3 & 0.8 & 0.8 & 7.7 & 0.6 & 0.7 & 0.8 & 0.5 & 0.6 & 1.0 & 1.0 & 1.0 & 1.0 & 0.9 & \\
\hline & 6-DUR-MC335 & 1.0 & 0.8 & 0.7 & 0.8 & 0.3 & 0 & 0.9 & 1.0 & 0.8 & 0.7 & 0.9 & 0.9 & 0.6 & 1.0 & 1.0 & 1.0 & 1.0 & 1.0 & 0.9 & 1. \\
\hline & 7-DUR-MC295 & 1.0 & 1.0 & 0.6 & 0.0 & 0.8 & 0.9 & 0 & 0.0 & 0.0 & 0.4 & 0.1 & 0.0 & 0.2 & 1.0 & 1.0 & 1.0 & 1.0 & 1.0 & 1.0 & 1.1 \\
\hline & 8-DUR-MC295 & 1.0 & 1.0 & 0.7 & 0.1 & 0.8 & 1.0 & 0.0 & 0 & 0.0 & 0.4 & 0.1 & 0.0 & 0.3 & 1.0 & 1.0 & 1.0 & 1.0 & 1.0 & 1.0 & 1. \\
\hline & 9-DUR-MC252 & 1.0 & 1.0 & 0.6 & 0.0 & 0.7 & 0.8 & 0.0 & 0.0 & 0 & 0.4 & 0.0 & 0.0 & 0.1 & 1.0 & 1.0 & 1.0 & 1.0 & 1.0 & 1.0 & 1. \\
\hline & 10-DUR-MC252 & 0.8 & 0.7 & 0.1 & 0.3 & 0.6 & 0.7 & 0.4 & 0.4 & 0.4 & 0 & 0.2 & 0.3 & 0.1 & 0.9 & 0.8 & 0.7 & 0.7 & 0.7 & 0.7 & 0. \\
\hline & 11-DUR-MC252 & 1.0 & 0.9 & 0.5 & 0.0 & 0.7 & 0.9 & 0.1 & 0.1 & $v$ & 0.2 & 0 & 0.0 & 0.1 & 1.0 & 1.0 & 1.0 & 1.0 & 1.0 & 1.0 & 1 \\
\hline & 12-DUR-MC252 & 1.0 & 1.0 & 0.6 & 0.0 & 0.8 & 0.9 & 0.0 & 0.0 & 0.0 & 0.3 & 0.0 & 0 & 0.2 & 1.0 & 1.0 & 1.0 & 1.0 & 1.0 & 1.0 & 1 \\
\hline & DUR-MC205 & 0.9 & 0.8 & 0.3 & 0.1 & 0.5 & 0.6 & 0.2 & 0.3 & 0.1 & 0.1 & 0.1 & 0.2 & 0 & 0.9 & 0.9 & 0.9 & 0.9 & 0.9 & 0.9 & 0. \\
\hline \multirow{7}{*}{ 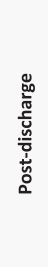 } & 14-POS & 0.8 & 0.8 & 0.8 & 1.0 & 0.6 & 1.0 & $|1.0|$ & 1.0 & 1.0 & 0.9 & 1.0 & 1.0 & 0.9 & 0 & 0.7 & 0.7 & 0.7 & 0.7 & 0.7 & 0. \\
\hline & OST-MC298 & 0.3 & 0.3 & 0.5 & 1.0 & 1.0 & $|1.0|$ & $|1.0|$ & 1.0 & 1.0 & 0.8 & 1.0 & 1.0 & 0.9 & 0.7 & 0 & 0.1 & 0.4 & 0.1 & 0.2 & 0 \\
\hline & 16-POST-MC297 & 0.3 & 0.3 & 0.5 & 1.0 & 1.0 & 1.0 & 1.0 & 1.0 & 1.6 & 0.7 & 1.0 & 1.0 & 0.9 & 0.7 & 0.1 & 0 & 0.4 & 0.0 & 0.1 & 0. \\
\hline & 17-POST-GC600 & 0.5 & 0.6 & 0.7 & 1.0 & 1.0 & 1.0 & 1.0 & 1.0 & $1 . \mathrm{v}$ & 0.7 & 1.0 & 1.0 & 0.9 & 0.7 & 0.4 & 0.4 & 0 & 0.3 & 0.3 & 0 \\
\hline & POST- & 0. & 0.3 & 0. & 1.0 & 1.0 & 1.0 & 1.0 & 1.0 & & 0. & 1.0 & 1.0 & 0.9 & 0.7 & 0.1 & 0.0 & 0.3 & 0 & 0.1 & 0 \\
\hline & 19-POST-MC252 & 0.4 & 0.4 & 0.5 & 1.0 & 0.9 & 0.9 & 1.0 & 1.0 & 1.0 & 0.7 & 1.0 & 1.0 & 0.9 & 0.7 & 0.2 & 0.1 & 0.3 & 0.1 & 0 & 0. \\
\hline & 20-POST-MC253 & 0.3 & 0.4 & 0.5 & 1.0 & 1.0 & $\mid 1.0$ & $\mid 1.0$ & 1.0 & 10 & 0.7 & 1.0 & 1.0 & 0.9 & 0.7 & 0.2 & 0.1 & 0.3 & 0.0 & 0.1 & \\
\hline
\end{tabular}

Figure 1 Heatmaps illustrating the dissimilarity of deep-sea microbial communities from samples obtained before, during and after the DWH discharge based on OTUs (a) and oligotypes (Oceaniserpentilla, Cycloclasticus, Colwellia, and SAR11; b). DWH-impacted sites were compared with natural hydrocarbon seeps in the Gulf of Mexico, MC118 (1-PRE-MC118 and 2-PRE-MC118) and GC600 (17-POST-GC600 and 18-POST-GC600). Dissimilarity measures from 0 to 1 (color coded as blue-white-red) were calculated using the MorisitaHorn index. 

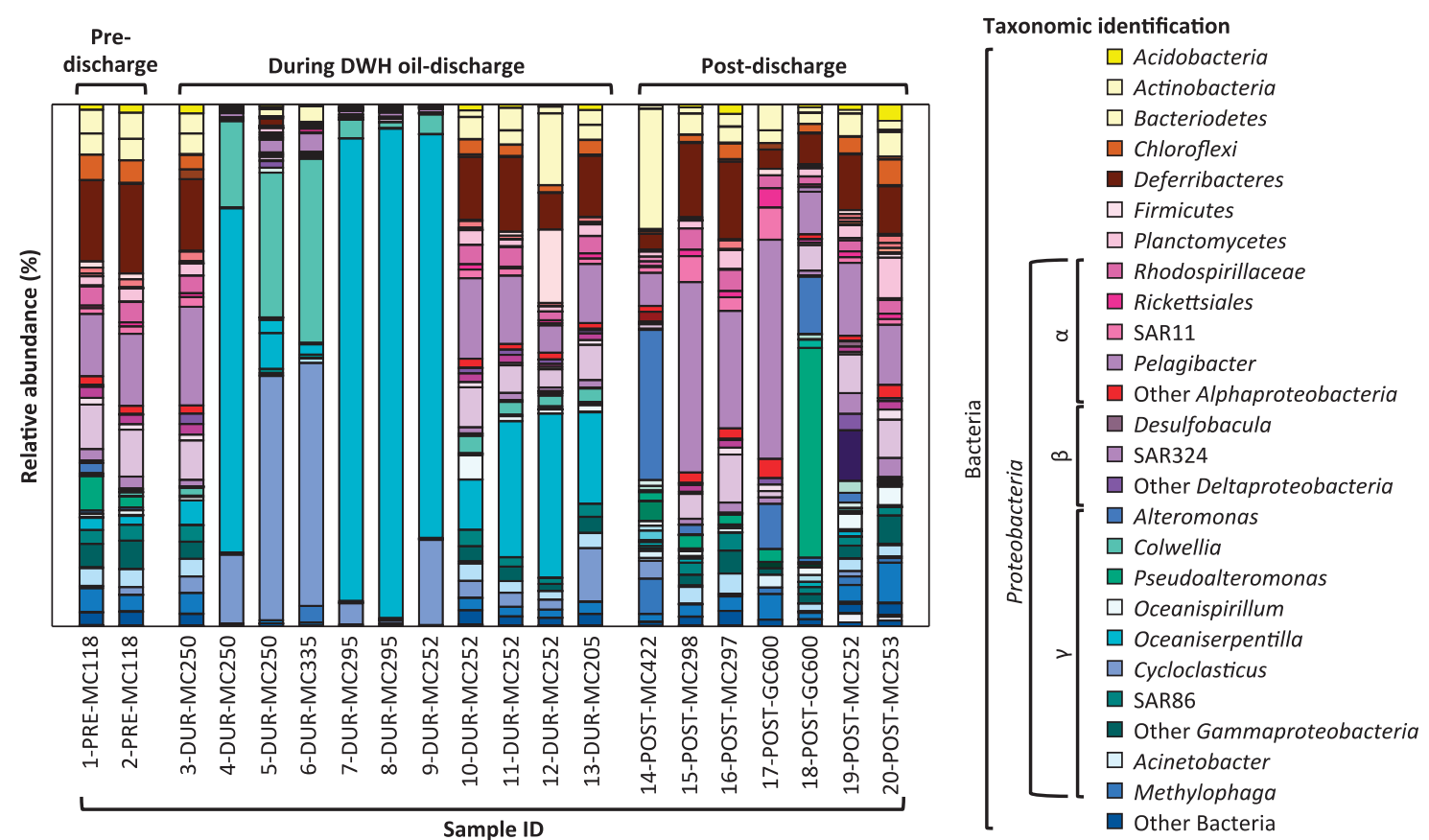

Figure 2 Relative abundances of bacterial populations throughout the time series (pre-discharge, during oil discharge and after discharge), along a vertical transect through different water depths $(603-1564 \mathrm{~m})$ and at two natural hydrocarbon seeps, MC118 (1-PRE-MC118 and 2PRE-MC118) and GC600 (17-POST-GC600 and 18-POST-GC600). Bacterial communities were analyzed using 454 pyrosequencing of the V6V4 region of the bacterial 16S rRNA gene. Dates of sampling, specific water depth and locations are given in Table 1.

a more modest $23-29 \%$ of all sequences in pre-discharge samples. Gammaproteobacteria affiliated with hydrocarbon degraders of Oceaniserpentilla (previously referred to DWH Oceanospirillum, for example, Hazen et al., 2010; Redmond and Valentine, 2012), Colwellia or Cycloclasticus, comprised up to $94 \%$ (Oceaniserpentilla; 8-DURMC295), 35\% (Colwellia; 6-DUR-MC335) and 47\% (Cycloclasticus; 5-DUR-MC250 and 6-DUR-MC335) of all bacterial sequences in discharge samples.

In September 2010, the biogeochemical signatures of the deepwater plume were largely attenuated (for example, methane concentrations were $\sim 1$ nM near the wellhead; Supplementary Table S1; Crespo-Medina et al., 2014). At this time, methylotrophic bacteria of the genus Methylophaga, which was below detection in pre-discharge sample, were enriched, accounting for $7 \%$ of all sequences (14-POST-MC422; Figure 2). Interestingly, Methylophaga were also detected in one sample from GC600 (1-2\% of all sequences, 17-POST-GC600; Figure 2), and in two samples retrieved from the DWH-impacted area in November 2012, including a sample directly taken over the wellhead (20-POSTMC253 and 19-POST-MC252). Methylophaga are known methylotrophs-potentially degrading by-products of complex oil biodegradation-but may also oxidize hexadecane, giving these microorganisms a potentially important role in hydrocarbon cycling at natural seeps. In addition, Bacteroidetes were highly enriched in postdischarge samples $(23 \%$ of all sequences, 14 -
POST-MC422; Figure 2,Supplementary Table S3) compared with pre-discharge and discharge samples ( $4 \%$ and $14 \%$ of all sequences, respectively). Like Methylophaga, the Bacteroidetes may potentially consume secondary metabolites of the biodegradation of methane or oil-derived compounds.

Members of the genus Alteromonas bloomed in the post-discharge environment $(29 \%$ of all sequences, 14-POST-MC422; Figure 2). These taxa, which occur also in natural seep samples albeit with reduced abundance (1-PRE-MC118; 2\%, 17-POST-GC600; 9\% and 18-POST-GC600; 11\%), may function as indigenous PAH degraders (Jin et al., 2012; Math et al., 2012). The sample from GC600, a prolific natural hydrocarbon seep, hosted abundant Pseudoalteromonas populations as well $(40 \%$ of all sequences, 18POST-GC600); these microbes may also degrade PAHs (Hedlund and Staley, 2006). We detected Pseudoalteromonas only in natural seep and postdischarge samples (2-7\% of all sequences), and not in samples collected during the discharge. It is possible that this microbial group could not cope with the environmental conditions during the discharge; alternatively, these organisms could have responded so rapidly to have bloomed and crashed between our sampling efforts and, thus, may have been missed.

Oligotype diversity among key hydrocarbon degraders Oligotyping is significantly advancing the field of microbial ecology (Eren et al., 2013) by providing insight to the subtle sequence variation between 
virulent and nonpathogenic microorganisms (Eren et al., 2011), host-specific fecal-indicator bacteria (McLellan et al., 2013), marine SAR11 oligotypes (Eren et al., 2013) and host-specificity in spongehosted microbial communities (Reveillaud et al., 2014). Importantly, the method is immune to complications originating from the occurrence of multiple copies of the 16S rRNA gene. For example, if two different oligotypes were from the same genome, they should always co-occur in data sets including that genome. This was never detected in the present data set. Instead, oligotypes had differential appearance patterns, which cannot be explained by the presence of multiple gene copies. Thus, oligotyping enhances the interpretation of $16 \mathrm{~S}$ rRNA gene sequence diversity, enabling quantification of ecologically relevant changes in microbial populations at the level of specific ecotypes (Ward, 1998; Eren et al., 2013). We resolved 21 Oceaniserpentilla oligotypes (representing $97.4 \%$ of all reads in that genus), 31 Cycloclasticus oligotypes (92.4\%) and 26 Colwellia oligotypes (94\%). Each oligotype had a minimum of $96 \%$ similarity to sequences in the NCBI nr database. Oceaniserpentilla oligotypes were between 97 and 99\% similar to sequenced representatives of Oceaniserpentilla haliotis (NR_042641.1); Cycloclasticus oligotypes had a 96$100 \%$ match to Cycloclasticus zancles (NC_021917.1) and Cycloclasticus sp. P1 (NC_018697.1); and, Colwellia oligotypes were $96-100 \%$ similar to Colwellia psychrerythraea (NC_003910.7).

We also performed oligotyping on 64701 SAR11classified sequences to assess whether the procedure on another ubiquitous member of the microbial community would generate distribution patterns lacking a clear meaningful ecological signal. In similar manner, we selected 14 high-entropy nucleotide positions that generated 98 oligotypes. All generated SAR11 oligotypes were at least 98\% similar to representatives in NCBI nr database. In contrast to the procedure with the other oligotyped taxa, increasing the number of nucleotide positions per iteration of oligotyping did not distinguish differential abundance patterns of SAR11 oligotypes within samples.

When probing this comprehensive spatially and temporally diverse data set via oligotyping, Morisita-Horn indexes revealed very similar patterns compared with the results we obtained for all OTUs (Figures 1a and b), implying that the alteration of the microbial community is explained primarily by variations in Oceaniserpentilla, Cycloclasticus and Colwellia oligotypes. Oligotype compositions in discharge samples were dissimilar to pre- and post-discharge samples (MorisitaHorn indexes 0.5-1, respectively; Figure 1b), showing that unique ecotypes occurred at specific times before, during and after the discharge.

Examining relative abundances on the sub-OTU level revealed previously unrecognized distinct taxa within Oceaniserpentilla, Cycloclasticus and Colwellia that reflected meaningful ecological variation.
Oligotypes enriched in samples collected during the discharge, when hydrocarbon availability was very large in the deepwater plume, represented unique populations compared with those dominating natural seeps or out of plume samples, where the hydrocarbon availability was much lower. In ecology, the concept of $\mathrm{r}$ and $\mathrm{K}$ strategists refers to the growth rate of a population and the carrying capacity of a specific environment (Andrews and Harris, 1986). We propose that taxa enriched during the oil spill in the hydrocarbon-enriched deepwater plume were fast growing r-strategists able to quickly respond to changing conditions, compared with slow growing $\mathrm{K}$ strategists that inhabit environments with more stable conditions. Although natural seeps can be either characterized by slow-diffuse or pulsed rapid hydrocarbon seepage (K- vs r-strategists), the DWH discharge apparently offered an advantageous environmental niche for r-strategists.

Profound changes in distributions of Oceaniserpentilla, potential cycloalkane oxidizers (Mason et al., 2012), were detected in response to the DWH oil discharge compared with pre-discharge conditions. Exploring Oceaniserpentilla oligotype distribution, pre-discharge samples (1-PRE-MC118 and 2-PRE-MC118; Morisita-Horn index 1.0; Supplementary Figure S2a) were dissimilar to all other samples. Pre-discharge abundant oligotypes (type_18, type_19; Figure 3) were not detected during or after the DWH discharge. Based on phylogenetic analysis of nearly full-length $16 \mathrm{~S}$ rRNA gene sequences along with oligotype sequences, pre-discharge oligotypes (type_18, type_19) closely affiliated with taxa not associated with the DWH oil discharge, likely reflecting the natural background community. In contrast, during the discharge, different Oceaniserpentilla oligotypes (type_01, type_02, type_10; Figure 3) were observed that are related to spp. detected in DWH oil-plume samples in prior studies (for example, acc. nos. JN015209, HM587888-90; Supplementary Figure S3; Hazen et al., 2010). After the discharge, abundant Oceaniserpentilla oligotypes (type_10, $\leqslant 6 \%$, type_16, $\leqslant 5 \%$, type_21, $\leqslant 92 \%$ of all oligotypes, respectively; Figure 3), were closely related to spp. detected during the DWH oil discharge (for example, acc. nos. HM587889, JN015210; Supplementary Figure S3; Hazen et al., 2010) as well as to spp. identified during ${ }^{13} \mathrm{C}$-ethane and ${ }^{13} \mathrm{C}$-propane stable-isotope probing experiments with Gulf seawater (for example, acc. nos. JN018486, JN018459; Redmond and Valentine, 2012) and to spp. not associated with the DWH discharge. It remains unclear whether changes in the Oceaniserpentilla oligotypes abundant during and after the spill (type_10, type_21) as well as an oligotype that enriched after the DWH oil discharge (type_16, 25\% of all oligotypes, 18-POST-GC600) reflect a long-term impact of the spill.

For the potential PAH degraders affiliating with Cycloclasticus (Dyksterhouse et al., 1995), ecotype distribution was similar pre- and during 


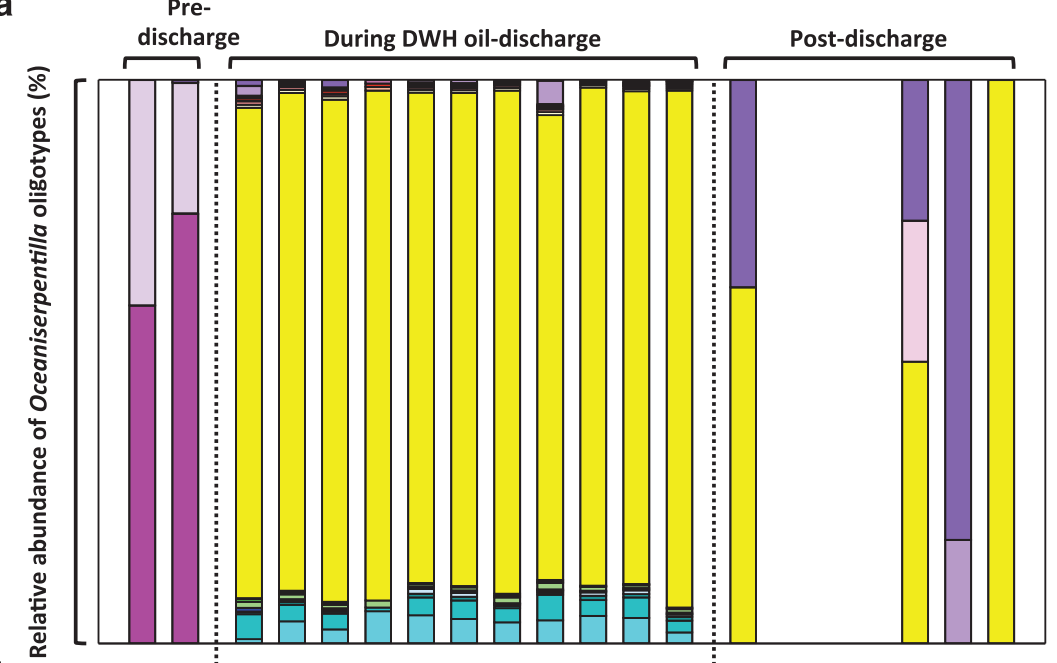

b

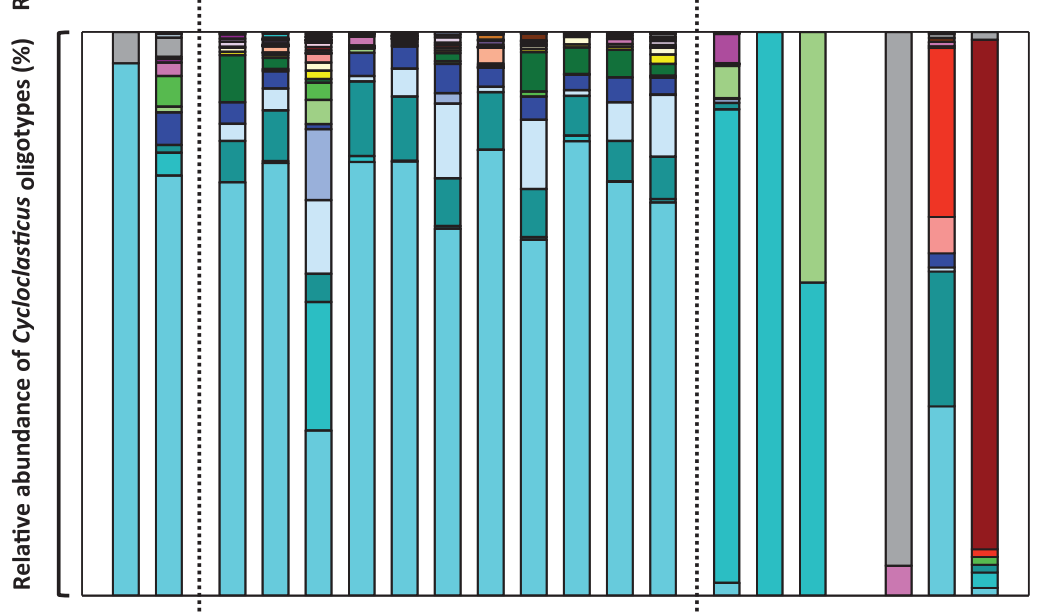

Oligotype

$\square 1$

$\square 2$

$\square 3$

$\square 4$

$\square 5$

$\square 6$

$\square 7$

$\square 8$

9

$\square 10$

$\square 11$

$\square 12$

$\square 13$

$\square 14$

15

$\square 16$

$\square 17$

ㅁ 18

$\square \quad 19$

ㄴ 20

口 21

口 22

$\square \quad 23$

$\square \quad 24$

- 25

$\square \quad 26$

$\square \quad 27$

$\square \quad 28$

- 29

- 30

$\square \quad 31$

C
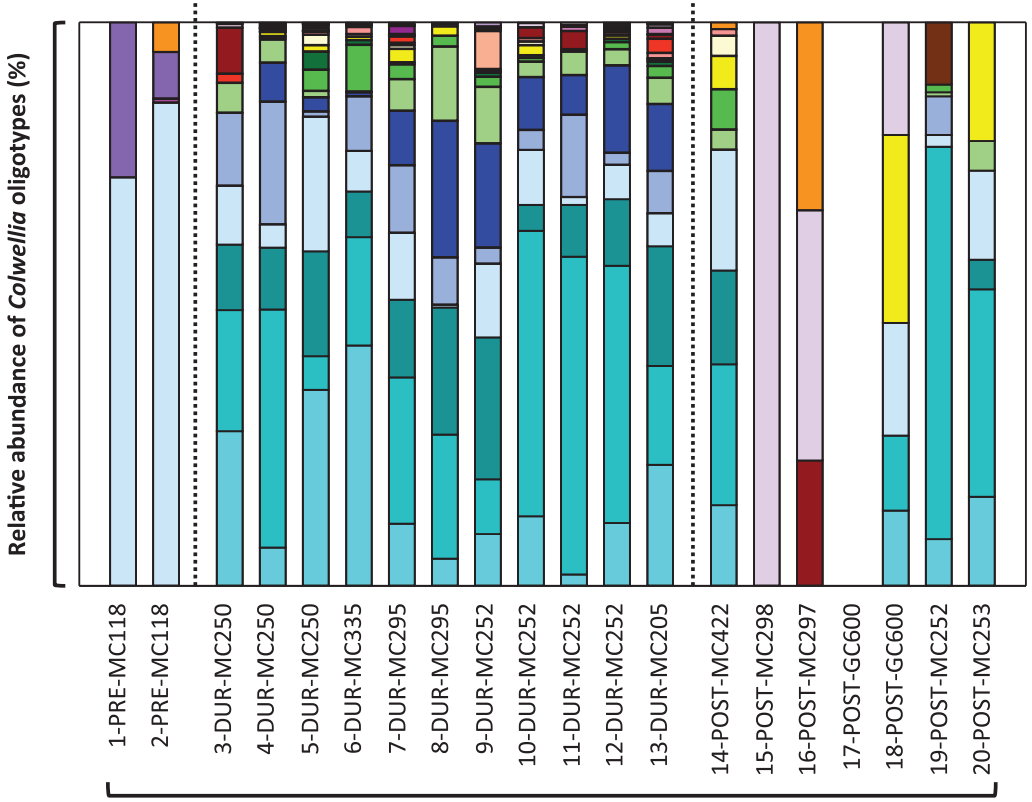

Sample ID

Figure 3 Relative abundances of Oceaniserpentilla oligotypes (a), Cycloclasticus oligotypes (b) and Colwellia oligotypes (c) that had a key role during the DWH oil spill. Oligotyping enabled the interpretation of $16 \mathrm{~S}$ rRNA gene sequence diversity at the level of specific ecotypes. Dynamics of oligotypes were monitored in pre-discharge, discharge and post-discharge samples. 
the discharge (Morisita-Horn index <0.1-0.5; Supplementary Figure S2b). Post-discharge, three samples revealed similar Cycloclasticus ecotypes (14-POST-MC422, 15-POST-MC298 and 16-POSTMC297; Morisita-Horn index $<0.1-0.3$ ), whereas an additional three samples were unique (18-POSTGC600, 19-POST-MC252 and 20-POST-MC253; Morisita-Horn index 0.9-1). The dominant oligotype detected before the DWH incident (type_01, 74-94\% of all oligotypes, 1-PRE-MC118 and 2-PRE-MC118; Figure 3) was present in high abundance during (29-81\% of all oligotypes) and after the discharge (up to $34 \%$ of all oligotypes, 19-POST-MC252). This oligotype_01 is phylogentically affiliated with spp. detected in the deepwater plume samples in previous studies (acc. nos. JN018748, JN018827, JN018869, JN018988 and HQ222992; Supplementary Figure S4; Redmond and Valentine, 2012; Valentine et al., 2012). In addition, Cycloclasticus oligotypes (type_02, type_07) abundant in post-discharge samples (up to $100 \%$ and $44 \%, 15$-POST-MC298 and 16POST-MC297; Figure 3) clustered with spp. detected in samples from previous DWH studies (HQ433397, JN019017, HQ222993; Valentine et al., 2010; Kessler et al., 2011b; Redmond and Valentine, 2012). The distributions of these oligotypes show that the Cycloclasticus inhabiting natural hydrocarbon seeps in the Gulf were apparently able to withstand the environmental perturbations resulting from the DWH discharge and probably participated in oil biodegradation during the incident.

For the Colwellia, which contain putative shortchain alkane degraders (Redmond and Valentine, 2012), oligotype distribution revealed similar patterns pre-discharge (Morisita-Horn index <0.1; Supplementary Figure S2c) and during the discharge (Morisita-Horn index 0.1-0.8), respectively. We detected one oligotype (type_04) throughout the time series. Phylogenetic analysis showed that this oligotype was closely related to organisms detected in both natural seep samples and in DWH-impacted samples (Figure 4; acc. nos. JN018846; Redmond and Valentine, 2012), showing that some Colwellia spp. present at natural hydrocarbon seeps were able to cope with the high gas, oil and dispersant concentrations present in deepwater during the DWH discharge. However, the relative abundance of this oligotype decreased significantly during the discharge compared with pre-discharge samples (from $72-86 \%$ to $0-13 \%$ of all oligotypes; Figure 3), implying that non-seep native microorganisms dominated the Colwellia population during the spill. In line with this, the most abundant Colwellia oligotypes during the DWH discharge (type_01, $\leqslant 43 \%$, type_02, $\leqslant 56 \%$, type_03, $\leqslant 25 \%$, type_05, $\leqslant 22 \%$, type_06, $\leqslant 24 \%$, type_07, $\leqslant 13 \%$ and type_08, $\leqslant 8 \%$ of all oligotypes, respectively; Figure 3) were closely related to microbes detected in deepwater plume samples in previous studies (for example, acc. nos. JN018749, JN018846 and JN019018; Redmond and Valentine, 2012) or to organisms identified in stable-isotope probing experiments with ${ }^{13} \mathrm{C}$-methane, ${ }^{13} \mathrm{C}$-ethane and ${ }^{13} \mathrm{C}$-propane (acc. nos. JN018467, JN018427, JN018472 and JN019018; Redmond and Valentine, 2012; Figure 4). Colwellia oligotypes dominating samples during the discharge ( $>5 \%$ relative abundance during the $\mathrm{DWH}$ oil spill; Figure 4) appeared strikingly diverse in the $16 \mathrm{~S}$ rRNA gene tree and sequences scattered throughout the Colwelliaceae opposed to the formation of phylogenetically distinct clusters. The detected phylogenetic diversity of Colwellia during the DWH oil spill likely reflects the physiological diversity of this group and their ability to respond to a range of environmental conditions. Interestingly, Colwellia sp. RC25 isolated with MC252 oil from DWH-contaminated waters (Bælum et al., 2012) is not closely related to any of the taxa detected during the $\mathrm{DWH}$ oil discharge in previous reports or any of the Colwellia oligotypes reported here (Figure 4). Although the cultivar Colwellia sp. RC25 (Bælum et al., 2012) serves as a valuable model organism, its physiology (for example, substrate preferences, optimal growth conditions and activity) may not reflect that of the Colwellia ecotypes that dominated during the DWH discharge.

\section{Environmental factors driving oligotype distribution} and abundance

We further evaluated relationships between environmental parameters and the distributions of Colwellia, Cycloclasticus, Oceaniserpentilla oligotypes across samples using R (R-Core-Team, 2012), packages vegan (Oksanen et al., 2013) and qualue (Klaus and Strimmer, 2012). Spearman's rank correlation coefficient $\rho$ for each oligotype distribution and environmental parameter, and Storey's false discovery rate correction for multiple tests at $\mathrm{q}<0.05$ showed significant $(P<0.05)$ correlations. As oligotyping resolves subtle variations of $16 \mathrm{~S}$ rRNA genes that represent distinct ecotypes (Ward, 1998; Eren et al., 2013), we argue that oligotypes that correlate significantly with environmental parameters likely represent distinct ecotypes. The relative abundances of six Colwellia oligotypes (types_01, 02, 03, 04, 06, 09), three Cycloclasticus oligotypes (types_04, 06, 30) and one Oceaniserpentilla oligotype (type_17) strongly tracked the elevated methane concentrations in the deepwater hydrocarbon plume; these same samples also had high concentrations of colored dissolved organic matter, a good proxy for dissolved oil (Wade et al., 2013; Supplementary Table S5). The successive blooms of diverse Colwellia oligotypes likely reflect transitions between distinct ecological niches, such as different substrate preferences of specific short-chain alkanes, dispersants or other organic compounds. Furthermore, higher methane oxidation rate measurements correlated with higher abundances of three Colwellia oligotypes (types_01, 04 and 06) and three Cycloclasticus oligotypes (types_01, 06 and 30). To date, neither Colwellia nor Cycloclasticus are known to be methane oxidizers, that is, their genomes reveal no metabolic ability to 

Oligotype sequence \#
$100-1,000$
$1,000-10,000$

Oligotype relative abundance

$>5 \%$ during DWH oil spill

Oligotype significant correlation $\left[\mathrm{CH}_{4}\right]$ Methane

[MOx] Methane oxidation

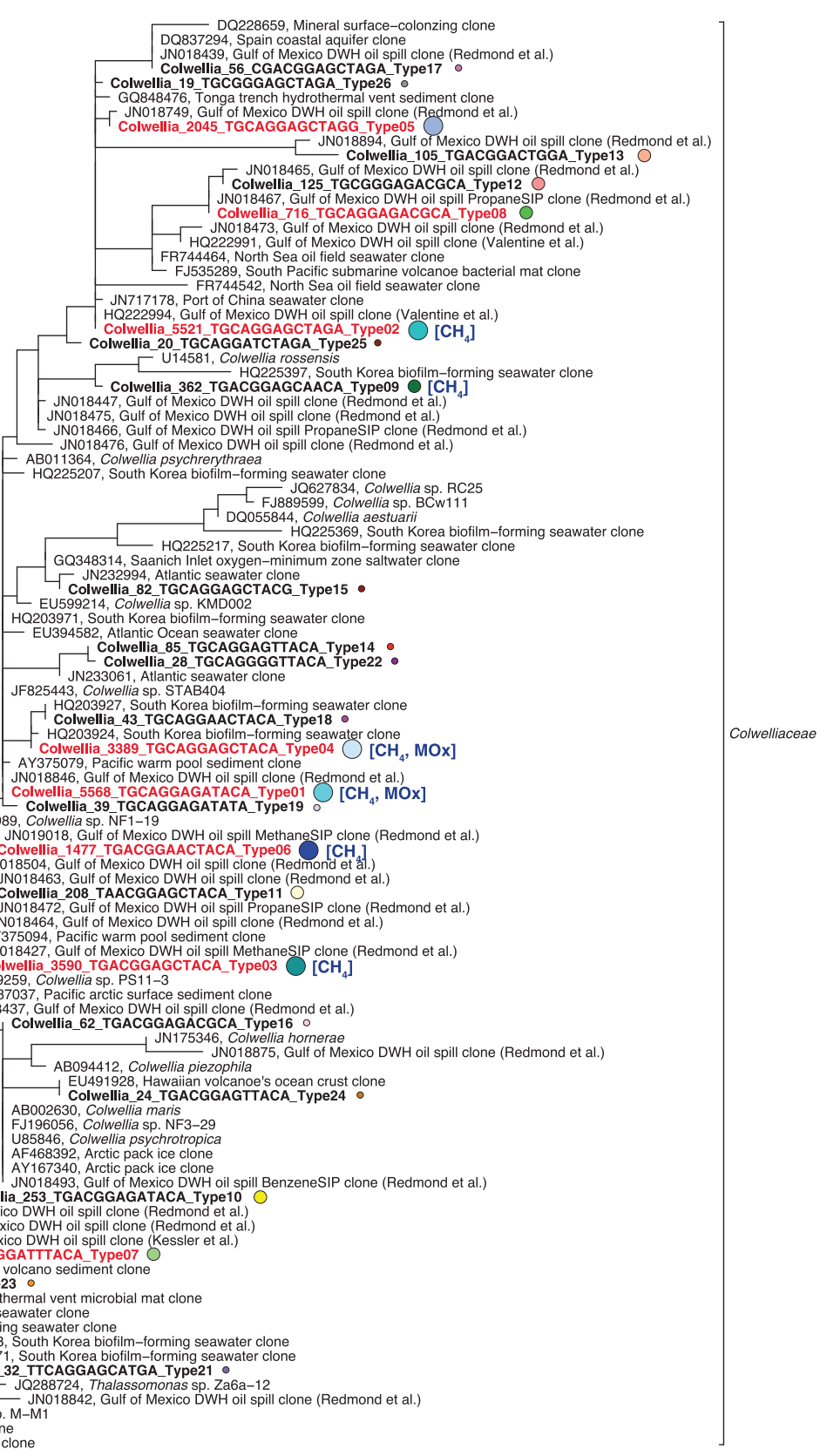

Methylophaga

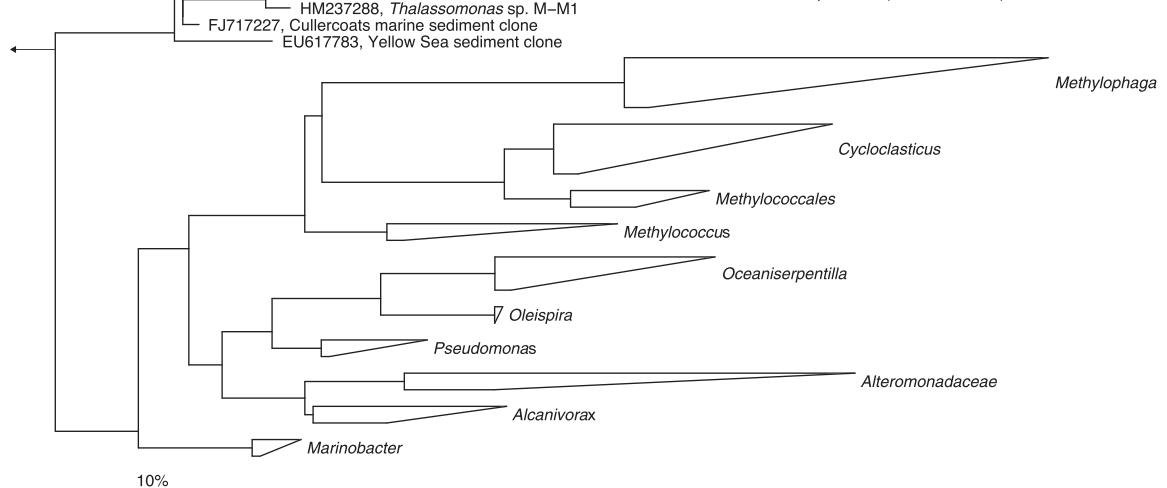

Figure 4 Phylogenetic relationships of Colwellia oligotypes (bold) with closely related spp. including cultured representatives. The tree was calculated by maximum-likelihood analysis. Oligotypes that were potentially more active during the DWH oil discharge are shown in red-colored font. Color-coding of spheres corresponds to oligotype labeling in Figure 3. Furthermore, oligotypes that significantly correlate with methane and/or methane oxidation are labeled with $\left[\mathrm{CH}_{4}\right]$ and/or [MOx]. The number of reads that clustered into the same oligotype is given in the full name. The bar represents $10 \%$ estimated sequence divergence. 
oxidize methane (Lai et al., 2012; Mason et al., 2014). However, the positive correlation of these oligotypes with methane oxidation rates implies either their indirect involvement in this process (for example, through oxidation of co-metabolites or reaction byproducts) or their coexistence with methane oxidizers (for example, in plume samples, where methane, alkanes and PAHs coexisted) or possibly an unrecognized potential to oxidize methane.

\section{Oligotype distribution patterns of the ubiquitous clade} SAR11

To ground truth the patterns observed in community succession of putative oil-oxidizing bacteria, we oligotyped a ubiquitous community member, SAR11, to confirm that the procedure did not generate patterns lacking clear ecological meaning (Supplementary Figures S2d and S5, Supplementary Table S3). We evaluated relationships of the SAR11 population with environmental parameters as well. The relative abundances of 27 SAR11 oligotypes correlated negatively with cell counts, methane concentrations (types_42, 66 and 90) and methane oxidation rates (types_37, 42, 43, 66 and 90; Supplementary Table S5). Thus, oligotyping did not suggest any role for SAR11 in hydrocarbon dynamics, as expected from the known ecological and metabolic strategies of SAR11. The genomes of Pelagibacter spp. are optimized for lower energy needs and carbon starvation in oligotrophic open ocean conditions (Steindler et al., 2011). At depth in the northern Gulf of Mexico, SAR11 representation decreases, whereas hydrocarbon-associated gammaproteobacterial members such as Colwellia, Cycloclasticus and Oceaniserpentilla predominate (Giovannoni et al., 2005). Interestingly, two SAR11 oligotypes (types_68 and 73) showed strong positive correlations with NOx (nitrite plus nitrate) concentrations. Although SAR11 are globally abundant in marine seawater environments (Morris et al., 2002), both negative (Eiler et al., 2009) and positive (Teira et al., 2009) correlations of marine SAR11 to ammonium and nitrate concentration have been reported. Thus, SAR11 members may be specialized for ecological niches defined by the availability of nutrients.

\section{Conclusions}

Assessing the relative abundance of Oceaniserpentilla, Cycloclasticus and Colwellia oligotypes on the sub-OTU level in a spatially and temporally diverse data set obtained from natural seeps and areas impacted by the DWH oil spill in the Gulf revealed a previously unrecognized level of diversity of these hydrocarbon degraders and a clear evolution of taxa distribution over time during the DWH incident. Certain ecotypes inhabiting natural seeps were potentially able to cope with the deepwater plume conditions. However, the ingrowth of Oceaniserpentilla, Cycloclasticus and Colwellia was dominated by taxa usually not observed at natural hydrocarbon seeps. Future characterizations of these potentially specialized ecotypes, through culturing and physiological experiments, and additional analyses of both functional and marker genes, will advance the knowledge of their ecological relevance in the marine environment. In addition, such analyses will provide more insights into the environmental factors that drove their increased dominance during the oil spill.

Oligotyping provided a way to quantify, with great precision, the response of microbial taxa likely representing distinct ecotypes during this acute environmental perturbation. Similarly, this approach is suitable for assessing taxa evolution in response to other acute and chronic environmental perturbations, such as eutrophication, hurricanes, tsunamis or climate change. Diverse low-abundance, likely specialized taxa responded to the DWH hydrocarbon infusion within a few weeks. The ability of these members of the rare biosphere to boost activity and abundance following a massive perturbation illustrates the diverse and large metabolic potential of the Gulf's natural microbial population.

\section{Conflict of Interest}

The authors declare no conflict of interest.

\section{Acknowledgements}

This research was supported by the US National Science Foundation's Biological and Chemical Oceanography Programs (OCE-1043225 to SBJ), the NOAA National Institute for Undersea Science and Technology (award numbers 0710028 and 0810031 to SBJ), a grant from BP/The Gulf of Mexico Research Initiative to support the 'Ecosystem Impacts of Oil and Gas Inputs to the Gulf (ECOGIG)' consortium, and the Sloan Foundation's Deep Carbon Observatory and Census of Marine Life Programs (to MS). This is ECOGIG contribution 203 and the data are deposited under GRIIDC acquisition number (UDI: R1.x132.134:0079).

\section{References}

Aharon P. (1994). Geology and biology of modern and ancient submarine hydrocarbon seeps and vents: an introduction. Geo-Mar Lett 14: 69-73.

Andrews J, Harris R. (1986). r- and K-selection and microbial ecology. In: Marshall KC (ed) Advances in Microbial Ecology. Springer: New York, NY, USA, pp 99-147.

Bælum J, Borglin S, Chakraborty R, Fortney JL, Lamendella $\mathrm{R}$, Mason OU et al. (2012). Deep-sea bacteria enriched by oil and dispersant from the Deepwater Horizon spill. Environ Microbiol 14: 2405-2416.

Behrens EW. (1988). Geology of a continental slope oil seep, northern Gulf of Mexico. AAPG Bull 72: 105-114.

Bowles MW, Samarkin VA, Bowles KM, Joye SB. (2011). Weak coupling between sulfate reduction and the anaerobic oxidation of methane in methane-rich seafloor sediments during ex situ incubation. Geochim Cosmochim Acta 75: 500-519. 
Camilli R, Reddy CM, Yoerger DR, Van Mooy BA, Jakuba MV, Kinsey JC. (2010). Tracking hydrocarbon plume transport and biodegradation at Deepwater Horizon. Science 330: 201-204.

Cardona Y, Bracco A. (2015). Predictability of mesoscale circulation throughout the water column in the Gulf of Mexico. Deep-Sea Res Pt II; doi:10.1016/j.dsr2.2014.01.008.

Carini S, Bano N, LeCleir G, Joye SB. (2005). Aerobic methane oxidation and methanotroph community composition during seasonal stratification in Mono Lake, California (USA). Environ Microbiol 7: 1127-1138.

Crespo-Medina M, Hunter KS, Meile CD, Diercks AR, Asper V, Orphan VJ et al. (2014). The rise and fall of methanotrophy following a deepwater oil-well blowout. Nat Geosci 7: 423-427.

Diercks A-R, Highsmith RC, Asper VL, Joung D, Zhou Z, Guo L et al. (2010). Characterization of subsurface polycyclic aromatic hydrocarbons at the Deepwater Horizon site. Geophys Res Lett 37: L20602.

Dyksterhouse SE, Gray JP, Herwig RP, Lara JC, Staley JT. (1995). Cycloclasticus pugetii gen. nov., sp. nov., an aromatic hydrocarbon-degrading bacterium from marine sediments. Int J Syst Bacteriol 45: 116-123.

Edgar RC. (2010). Search and clustering orders of magnitude faster than BLAST. Bioinformatics 26: 2460-2461.

Eiler A, Hayakawa DH, Church MJ, Karl DM, Rappé MS. (2009). Dynamics of the SAR11 bacterioplankton lineage in relation to environmental conditions in the oligotrophic North Pacific subtropical gyre. Environ Microbiol 11: 2291-2300.

Eren AM, Zozaya M, Taylor CM, Dowd SE, Martin DH, Ferris MJ. (2011). Exploring the diversity of Gardnerella vaginalis in the genitourinary tract microbiota of monogamous couples through subtle nucleotide variation. PLoS One 6: e26732.

Eren AM, Maignien L, Sul WJ, Murphy LG, Grim SL, Morrison HG et al. (2013). Oligotyping: differentiating between closely related microbial taxa using $16 \mathrm{~S}$ rRNA gene data. Methods Ecol Evol 4: 1111-1119.

Giovannoni SJ, Tripp HJ, Givan S, Podar M, Vergin KL, Baptista $\mathrm{D}$ et al. (2005). Genome streamlining in a cosmopolitan oceanic bacterium. Science 309: 1242-1245.

Hazen TC, Dubinsky EA, DeSantis TZ, Andersen GL, Piceno YM, Singh N et al. (2010). Deep-sea oil plume enriches indigenous oil-degrading bacteria. Science 330: 204-208.

Hedlund BP, Staley JT. (2006). Isolation and characterization of Pseudoalteromonas strains with divergent polycyclic aromatic hydrocarbon catabolic properties. Enironm Microbiol 8: 178-182.

Hobbie JE, Daley RJ, Jasper S. (1977). Use of nuclepore filters for counting bacteria by fluorescence microscopy. Appl Environ Microbiol 33: 1225-1228.

$\mathrm{Hu}$ L, Yvon-Lewis SA, Kessler JD, MacDonald IR. (2012). Methane fluxes to the atmosphere from deepwater hydrocarbon seeps in the northern Gulf of Mexico. J Geophys Res 117: C01009.

Huse SM, Dethlefsen L, Huber JA, Welch DM, Relman DA, Sogin ML. (2008). Exploring microbial diversity and taxonomy using SSU rRNA hypervariable tag sequencing. PLoS Genet 4: e1000255.

Huse SM, Welch DM, Morrison HG, Sogin ML. (2010). Ironing out the wrinkles in the rare biosphere through improved OTU clustering. Environ Microbiol 12: 1889-1898.

Jin HM, Kim JM, Lee HJ, Madsen EL, Jeon CO. (2012). Alteromonas as a key agent of polycyclic aromatic hydrocarbon biodegradation in crude oil-contaminated coastal sediment. Environ Sci Technol 46: 7731-7740.
Johansen Ø, Rye H, Melbye AG, Jensen HV, Serigstad B, Knutsen T. (2001). Deep Spill JIP Experimental Discharges of Gas and Oil at Helland Hansen - June 2000, Technical Report. SINTEF Applied Chemistry: Trondheim, Norway, p 159.

Joye SB, Boetius A, Orcutt BN, Montoya JP, Schulz HN, Erickson MJ et al. (2004). The anaerobic oxidation of methane and sulfate reduction in sediments from Gulf of Mexico cold seeps. Chem Geol 205: 219-238.

Joye SB, Bowles MW, Samarkin VA, Hunter KS, Niemann H. (2010). Biogeochemical signatures and microbial activity of different cold-seep habitats along the Gulf of Mexico deep slope. Deep-Sea Res Pt II 57: 1990-2001.

Joye SB, MacDonald IR, Leifer I, Asper V. (2011). Magnitude and oxidation potential of hydrocarbon gases released from the BP oil well blowout. Nature Geosci 4: 160-164.

Kennicutt II MC, Brooks JM, Denoux GJ. (1988). Leakage of deep, reservoired petroleum to the near-surface on the Gulf of Mexico continental-slope. Mar Chem 24: 39-59.

Kessler JD, Valentine DL, Redmond MC, Du M. (2011a). Response to comment on "a persistent oxygen anomaly reveals the fate of spilled methane in the deep Gulf of Mexico”. Science 332: 1033.

Kessler JD, Valentine DL, Redmond MC, Du M, Chan EW, Mendes SD. (2011b). A persistent oxygen anomaly reveals the fate of spilled methane in the deep gulf of Mexico. Science 331: 312-315.

Klaus B, Strimmer K. (2012), fdrtool: Estimation of (Local) False Discovery Rates and Higher Criticism. R package version 1.2.10.

Kleindienst S, Ramette A, Amann R, Knittel K. (2012). Distribution and in situ abundance of sulfate-reducing bacteria in diverse marine hydrocarbon seep sediments. Environ Microbiol 14: 2689-2710.

Konstantinidis KT, Tiedje JM. (2005). Genomic insights that advance the species definition for prokaryotes. Proc Natl Acad Sci USA 102: 2567-2572.

Konstantinidis KT, Ramette A, Tiedje JM. (2006). The bacterial species definition in the genomic era. Philosophical Trans R Soc B: Biol Sci 361: 1929-1940.

Kujawinski EB, Kido Soule MC, Valentine DL, Boysen AK, Longnecker K, Redmond MC. (2011). Fate of dispersants associated with the Deepwater Horizon oil spill. Environ Sci Technol 45: 1298-1306.

Kunin V, Engelbrektson A, Ochman H, Hugenholtz P. (2010). Wrinkles in the rare biosphere: pyrosequencing errors can lead to artificial inflation of diversity estimates. Environ Microbiol 12: 118-123.

Lai Q, Li W, Wang B, Yu Z, Shao Z. (2012). Complete genome sequence of the pyrene-degrading bacterium Cycloclasticus sp. strain P1. J Bacteriol 194: 6677.

Lloyd KG, Albert DB, Biddle JF, Chanton JP, Pizarro O, Teske A. (2010). Spatial structure and activity of sedimentary microbial communities underlying a Beggiatoa spp. mat in a Gulf of Mexico hydrocarbon seep. PLoS One 5: e8738.

Ludwig W, Strunk O, Westram R, Richter L, Meier H, Yadhukumar. (2004). ARB: a software environment for sequence data. Nucl Acids Res 32: 1363-1371.

Mason O, Han J, Woyke T, Jansson J. (2014). Single-cell genomics reveals features of a Colwellia species that was dominant during the Deepwater Horizon oil spill. Front Microbiol 5: 332.

Mason OU, Hazen TC, Borglin S, Chain PS, Dubinsky EA, Fortney JL et al. (2012). Metagenome, metatranscriptome 
and single-cell sequencing reveal microbial response to Deepwater Horizon oil spill. ISME J 6: 1715-1727.

Math RK, Jin HM, Kim JM, Hahn Y, Park W, Madsen EL et al. (2012). Comparative genomics reveals adaptation by Alteromonas sp. SN2 to marine tidal-flat conditions: cold tolerance and aromatic hydrocarbon metabolism. PLoS One 7: e35784.

McLellan SL, Newton RJ, Vandewalle JL, Shanks OC, Huse SM, Eren AM et al. (2013). Sewage reflects the distribution of human faecal Lachnospiraceae. Environ Microbiol 15: 2213-2227.

McNutt MK, Camilli R, Crone TJ, Guthrie GD, Hsieh PA, Ryerson TB et al. (2012). Review of flow rate estimates of the Deepwater Horizon oil spill. Proc Natl Acad Sci USA 109: 20260-20267.

Morris RM, Rappe MS, Connon SA, Vergin KL, Siebold WA, Carlson CA et al. (2002). SAR11 clade dominates ocean surface bacterioplankton communities. Nature 420: 806-810.

Oksanen J, Blanchet FG, Kindt R, Legendre P, Minchin PR, O'Hara RB et al. (2013), Vegan: Community Ecology Package. R package version 2.0-7.

Orcutt B, Boetius A, Elvert M, Samarkin V, Joye SB. (2005). Molecular biogeochemistry of sulfate reduction, methanogenesis and the anaerobic oxidation of methane at Gulf of Mexico cold seeps. Geochim Cosmochim Acta 69: 4267-4281.

Orcutt BN, Joye SB, Kleindienst S, Knittel K, Ramette A, Reitz A et al. (2010). Impact of natural oil and higher hydrocarbons on microbial diversity, distribution, and activity in Gulf of Mexico cold-seep sediments. DeepSea Res Pt II 57: 2008-2021.

Pruesse E, Quast C, Knittel K, Fuchs BM, Ludwig W, Peplies J. (2007). SILVA: a comprehensive online resource for quality checked and aligned ribosomal RNA sequence data compatible with ARB. Nucl Acids Res 35: 7188-7196.

Quast C, Pruesse E, Yilmaz P, Gerken J, Schweer T, Yarza P et al. (2013). The SILVA ribosomal RNA gene database project: improved data processing and webbased tools. Nucleic Acids Res 41: D590-D596.

R-Core-Team (2012). R: A Language and Environment for Statistical Computing. R Foundation for Statistical Computing: Vienna, Austria.

Reddy CM, Arey JS, Seewald JS, Sylva SP, Lemkau KL, Nelson RK. (2012). Composition and fate of gas and oil released to the water column during the Deepwater Horizon oil spill. Proc Natl Acad Sci USA 109: 20229-20234.

Redmond MC, Valentine DL. (2012). Natural gas and temperature structured a microbial community response to the Deepwater Horizon oil spill. Proc Natl Acad Sci USA 109: 20292-20297.

Reveillaud J, Maignien L, Eren AM, Huber JA, Apprill A, Sogin ML et al. (2014). Host-specificity among abundant and rare taxa in the sponge microbiome. ISME J 8: 1198-1209.

Roberts HH, Feng D, Joye SB. (2010). Cold-seep carbonates of the middle and lower continental slope, northern Gulf of Mexico. Deep-Sea Res Pt II 57: 2040-2054.

Sinigalliano CD, Gidley ML, Shibata T, Whitman D, Dixon TH, Laws E et al. (2007). Impacts of hurricanes Katrina and Rita on the microbial landscape of the New Orleans area. Proc Natl Acad Sci USA 104: 9029-9034.

Socolofsky SA, Adams EE, Sherwood CR. (2011). Formation dynamics of subsurface hydrocarbon intrusions following the Deepwater Horizon blowout. Geophys Res Lett 38: L09602.

Solorzano L. (1969). Determination of ammonia in natural waters by phenol hypochlorite method. Limnol Oceanogr 14: 799-801.

Steindler L, Schwalbach MS, Smith DP, Chan F, Giovannoni SJ. (2011). Energy starved Candidatus Pelagibacter ubique substitutes light-mediated ATP production for endogenous carbon respiration. PLoS One 6: e19725.

Swan BK, Martinez-Garcia M, Preston CM, Sczyrba A, Woyke T, Lamy D et al. (2011). Potential for chemolithoautotrophy among ubiquitous bacteria lineages in the dark ocean. Science 333: 1296-1300.

Teira E, Martínez-García S, Lønborg C, Álvarez-Salgado XA. (2009). Growth rates of different phylogenetic bacterioplankton groups in a coastal upwelling system. Environ Microbiol Rep 1: 545-554.

Thor Marteinsson V, Runarsson A, Stefansson A, Thorsteinsson T, Johannesson T, Magnusson SH et al. (2013). Microbial communities in the subglacial waters of the Vatnajokull ice cap, Iceland. ISME J 7: 427-437.

Tikhonov M, Leach RW, Wingreen NS. (2014). Interpreting $16 \mathrm{~S}$ metagenomic data without clustering to achieve sub-OTU resolution. ISME J. 9: 68-80.

Valentine DL, Kessler JD, Redmond MC, Mendes SD, Heintz MB, Farwell C. (2010). Propane respiration jump-starts microbial response to a deep oil spill. Science 330: 208-211.

Valentine DL, Mezić I, Maćešić S, Črnjarić-Žic N, Ivić S, Hogan PJ et al. (2012). Dynamic autoinoculation and the microbial ecology of a deep water hydrocarbon irruption. Proc Natl Acad Sci USA 109: 20286-20291.

Wade TL, Sweet ST, Sericano JL, Guinasso NL, Diercks A-R, Highsmith RC et al. (2013). Analyses of water samples from the Deepwater Horizon oil spill: documentation of the subsurface plumeMonitoring and Modeling the Deepwater Horizon Oil Spill: A Record-Breaking Enterprise. American Geophysical Union: Washington, DC, USA, pp 77-82.

Ward DM. (1998). A natural species concept for prokaryotes. Curr Opin Microbiol 1: 271-277.

Yakimov MM, Golyshin PN, Lang S, Moore ERB, Abraham W-R, Lünsdorf H et al. (1998). Alcanivorax borkumensis gen. nov., sp. nov., a new, hydrocarbon-degrading and surfactant-producing marine bacterium. Int J Syst Bacteriol 48: 339-348.

Zettler LA. (2013), DNA extraction from Sterivex filters using the Puregene kit. < http://amarallab.mbl.edu/ mirada/PuregeneDNAExtraction.html $>$.

(1) (5) This work is licensed under a Creative Commons Attribution-NonCommercialShareAlike 4.0 International License. The images or other third party material in this article are included in the article's Creative Commons license, unless indicated otherwise in the credit line; if the material is not included under the Creative Commons license, users will need to obtain permission from the license holder to reproduce the material. To view a copy of this license, visit http://creativecommons.org/ licenses/by-nc-sa/4.0/

Supplementary Information accompanies this paper on The ISME Journal website (http://www.nature.com/ismej) 